\title{
Hepatic transcriptomic adaptation from prepartum to postpartum in dairy cows
}

\author{
S. T. Gao, ${ }^{1}$ D. D. Girma, ${ }^{1 *}$ M. Bionaz, ${ }^{2}$ L. Ma, ${ }^{1} \dagger$ and D. P. Bu ${ }^{1} \dagger$ \\ ${ }^{1}$ State Key Laboratory of Animal Nutrition, Institute of Animal Science, Chinese Academy of Agricultural Sciences, Beijing, 100193, China \\ ${ }^{2}$ Department of Animal and Rangeland Sciences, Oregon State University, Corvallis 97331
}

\begin{abstract}
The transition from pregnancy to lactation is the most challenging period for high-producing dairy cows. The liver plays a key role in biological adaptation during the peripartum. Prior works have demonstrated that hepatic glucose synthesis, cholesterol metabolism, lipogenesis, and inflammatory response are increased or activated during the peripartum in dairy cows; however, those works were limited by a low number of animals used or by the use of microarray technology, or both. To overcome such limitations, an RNA sequencing analysis was performed on liver biopsies from 20 Holstein cows at $7 \pm 5 \mathrm{~d}$ before (Pre-P) and $16 \pm 2 \mathrm{~d}$ after calving (Post-P). We found 1,475 upregulated and 1,199 downregulated differently expressed genes (DEG) with a false discovery rate adjusted $P$-value $<0.01$ between Pre-P and Post-P. Bioinformatic analysis revealed an activation of the metabolism, especially lipid, glucose, and amino acid metabolism, with increased importance of the mitochondria and a key role of several signaling pathways, chiefly peroxisome proliferators-activated receptor (PPAR) and adipocytokines signaling. Fatty acid oxidation and gluconeogenesis, with a likely increase in amino acid utilization to produce glucose, were among the most important functions revealed by the transcriptomic adaptation to lactation in the liver. Although gluconeogenesis was induced, data indicated decrease in expression of glucose transporters. The analysis also revealed high activation of cell proliferation but inhibition of xenobiotic metabolism, likely due to the liver response to inflammatory-like conditions. Co-expression network analysis disclosed a tight connection and coordination among genes driving biological processes associated with protein synthesis, energy and lipid metabolism, and cell proliferation. Our data
\end{abstract}

Received June 17, 2020.

Accepted August 31, 2020.

*Current address: Ethiopian Biotechnology Institute, Addis Ababa, 1000 Ethiopia.

†Corresponding authors: budengpan@caas.cn and malu.nmg@163 com confirmed the importance of metabolic adaptation to lipid and glucose metabolism in the liver of early Post-P cows, with a pivotal role of PPAR and adipocytokines. Key words: RNA sequencing, peripartum cow, metabolic adaptation, hepatic transcriptome

\section{INTRODUCTION}

The transition from pregnancy to lactation is defined as the period between the last $3 \mathrm{wk}$ before parturition and the first 3 wk after parturition (Grummer, 1995; Drackley, 1999). This is a period of dramatic physiological and metabolic challenges for the dairy cow (Drackley et al., 2005; Loor et al., 2013), with increases of several fold in the requirements for energy, protein, and minerals within days of calving (Roche et al., 2017). The primary challenge experienced by transition cows is a sudden and large increase in nutrient requirements for milk production that is not satisfied by feed intake, with ensuing negative energy balance (Bell, 1995; Drackley, 1999). As a consequence, an array of maternal metabolic adaptations are activated, including increased hepatic gluconeogenesis from endogenous substrates, decreased peripheral glucose utilization, increased fatty acid mobilization from the adipose tissue, and, possibly, increased amino acid mobilization from muscle to meet the nutrient requirements during the transition period (Bell, 1995). However, important metabolic challenges can still weaken the immune system, contributing to increased incidence of diseases, including milk fever, ketosis, retained placenta, metritis, and displaced abomasum (Dohoo and Martin, 1984; Kremer et al., 1993; Duffield et al., 2002). Thus, physiological maladaptation during the peripartum negatively affects the net earnings of a dairy enterprise (Esposito et al., 2014; Roche et al., 2017).

The liver is a critical hub for numerous physiological processes, including macronutrient metabolism, blood volume regulation, immune system support, endocrine control of growth signaling pathways, lipid and cholesterol homeostasis, and the breakdown of xenobiotic toxic compounds (Piñeiro-Carrero and Piñeiro, 2004; 
Trefts et al., 2017). Liver also plays a critical role in the control of glucose homeostasis, especially via gluconeogenesis and storage of glucose via glycogen that is released during fasting conditions (Nordlie et al., 1999; Aschenbach et al., 2010). During prolonged fasting when the animals undergo negative energy balance, the liver also produces a high amount of ketone bodies to supply fuel to other organs (Lomax and Baird, 1983; Han et al., 2016; Trefts et al., 2017).

Because of the key role of the liver in controlling and regulating the metabolic adaptation during the peripartum (Drackley et al., 2005), several studies have been conducted to investigate liver adaptation to lactation. Those studies revealed that the liver during the adaptation to lactation augments the synthesis of glucose (Reynolds et al., 2003), cholesterol metabolism (Schlegel et al., 2012), and lipogenesis (Qin et al., 2018), and becomes more responsive to stimuli that induce inflammation (Loor et al., 2005). In addition, a recent hepatic transcriptomic study using RNA sequencing (RNAseq; Ha et al., 2017) confirmed that major hepatic changes during the peripartum in dairy cows are related to energy metabolism; in particular, they are related to fatty acid oxidation and metabolism, cholesterol metabolism, and gluconeogenesis.

However, most of the prior studies focused on specific aspects (Reynolds et al., 2003; Schlegel et al., 2012) and did not provide a comprehensive view of the adaptation of the liver to lactation even when high-throughput transcriptomic technologies were used, due to limitation of sensitivity typical of microarrays (Loor et al., 2005; Qin et al., 2018) or inadequate power analysis, as when only 6 cows were used per treatment (Ha et al., 2017). Thus, we found a lingering need for a study to comprehensively investigate the transcriptomic adaptation of the liver of dairy cows during the peripartum. To satisfy that need, the objective of the present study was to perform a comprehensive bioinformatic analysis of the transcriptomic adaptation of the liver using RNAseq on samples from a large number of peripartum dairy cows.

\section{MATERIALS AND METHODS}

\section{Ethics Statement}

This study was approved by the Animal Care and Use Committee of the Institute of Animal Science, Chinese Academy of Agricultural Sciences (No. IAS20180115; Beijing). Use of animals in the present study was in strict accordance with the Directions for Caring for Experimental Animals from the Institute of Animal Science, Chinese Academy of Agricultural Sciences.

\section{Experimental Animals and Management}

Liver tissues were collected from dairy cows from a larger experiment in which cows were enrolled in a 2 $\times 2$ factorial design with 2 dietary energy levels and supplemented or not with rumen-protected lysine during the peripartum (Girma et al., 2019). Liver biopsies were performed in 5 random animals per each group twice, at $7.3 \pm 5.1$ (mean $\pm \mathrm{SD}$ ) days before parturition (Pre-P) and at $16.4 \pm 2.3 \mathrm{~d}$ after parturition (Post$\mathbf{P})$. The specific biopsy date for each sample is available in Supplemental Table S1 (https://doi.org/10.3168/jds .2020-19101). Because of postpartum diseases, 2 cows died before the second biopsy. In addition, another cow was removed due to excessive distance from Pre-P during the first biopsy. Thus, we obtained 2 fewer liver samples of Post-P $(\mathrm{n}=17)$ than Pre-P $(\mathrm{n}=19)$. All the cows were in the same parity (third lactation), entering their fourth lactation, with BCS between 3.25 and 3.5 (1-5 scale). The expected calving date of each cow was considered in selecting cows with similar expected calving dates and previous milk yield. Throughout the experiment, cows were housed in a freestall ventilated enclosed barn, and the diet was formulated to meet requirements according to NRC (2001; Supplemental Table S2, https://doi.org/10.3168/jds.2020-19101) and provided as a TMR twice a day at 0600 and $1400 \mathrm{~h}$. Dry matter intake was determined by measuring feed provided and subtracting the orts remaining. Cows were moved into a maternity pen bedded with straw 3 $\mathrm{d}$ before expected parturition and moved back with the herd $21 \mathrm{~d}$ after parturition.

\section{Milk Sample Collection and Measurement}

Milk samples from individual cows were collected at 3 consecutive milkings and mixed based on the average milk production at each milking (morning, afternoon, and night; volume ratio of 4:3:3) on d 7, 14, and 21 . Milk samples were preserved with bronopol-B2 preservative (D and F Control Systems Inc., Dublin, ON, Canada) at $4^{\circ} \mathrm{C}$ and subsequently analyzed for fat, protein, lactose, and MUN using a mid-infrared machine (Foss MilkoScan, Foss Food Technology Corp., Eden Prairie, MN). The results of milk yield and composition are shown in Supplemental Table S3 (https://doi.org/ 10.3168/jds.2020-19101).

\section{Blood Sample Collection and Measurement}

Blood samples were collected from individual cows at $0700 \mathrm{~h}$ daily on $\mathrm{d}-21,-14,-7,0,3,7,14$, and 21 relative to calving, as described by Girma et al. (2019). 
All blood samples were collected in serum separator tubes (Serum Clot Activator, Greiner Bio-one GmbH, Kremsmunster, Austria), and the samples were allowed to clot for a minimum of $25 \mathrm{~min}$ at $20^{\circ} \mathrm{C}$ and stored in the refrigerator overnight. The samples were then centrifuged at $3,000 \times g$ for 15 min at $4^{\circ} \mathrm{C}$ before separation of the serum. Nonesterified fatty acid (NEFA), $\mathrm{BHB}$, and triglycerides in the blood were analyzed using commercial assay kits (Nanjing Jiancheng Bioengineering Institute, Nanjing Jiancheng Technology Co. Ltd., Nanjing, China) according to the manufacturer's instructions.

\section{Liver Tissue Sample Collection}

The liver biopsy procedure was conducted using a Tru-Cut biopsy needle (Baxter Healthcare Corp., Valencia, CA; diameter $4 \mathrm{~mm}$ ) as previously described (Bu et al., 2017). Briefly, before applying a local anesthetic, the cows received a small dose of xylazine (0.05 $\mathrm{mg} / \mathrm{kg}$ of BW). Three to four milliliters of lidocaine hydrochloride ( $2 \%$ solution) was injected subcutaneously as a local anesthetic before the incision. A $1.5-\mathrm{cm}$ incision using a sterile scalpel blade was made between the eleventh and twelfth ribs on the right side of the cow. Pressure was applied to the incision using sterile gauze, until visual signs of bleeding were absent. Then the liver biopsy was performed, obtaining $\sim 300 \mathrm{mg}$ of tissue. Tissue samples were washed with PBS buffer prepared with nuclease-free water and immediately stored in liquid nitrogen. Four or five Michel clips (11 mm; Henry Schein, Melville, NY) were used to close the skin incision after the biopsy. The incision site was sprayed with a topical antiseptic (10\% povidone iodine ointment; Taro Pharmaceuticals, Hawthorne, NY). For $7 \mathrm{~d}$ after the biopsy, health was monitored by recording rectal temperature and daily feed intake. After the incision was completely healed $(\sim 7 \mathrm{~d})$, the surgical clips were removed.

\section{RNA Isolation}

TRIzol reagent (Invitrogen, Carlsbad, CA) was used to isolate total RNA from each sample. The NanoPhotometer spectrophotometer (IMPLEN, Westlake Village, CA), the Qubit RNA Assay Kit in Qubit 2.0 Fluorometer (Life Technologies, Carlsbad, CA), and the RNA Nano 6000 Assay Kit of the Bioanalyzer 2100 System (Agilent Technologies, Santa Clara, CA) were used to detect RNA purity, concentration, and integrity of each sample. The optical density OD260/OD280 values were $\geq 1.9$, and the RNA integrity number values were $\geq 8.0$.

\section{Library Preparation and Sequencing}

Library preparation and sequencing were performed as previously described (Ren et al., 2016). Before library construction, rRNA was removed using Epicenter Ribo-Zero rRNA Removal Kit (Epicentre Biotechnologies, Madison, WI), and then further cleaned up using ethanol precipitation. Accurate $3-\mu \mathrm{g}$ RNA per sample was used as input for complementary DNA (cDNA) library construction. Sequencing libraries were generated using the rRNA-depleted RNA following manufacturer's recommendations, using the NEBNext Ultra Directional RNA Library Prep Kit for Illumina (New England Biolabs, Ipswich, MA). The RNA sequencing was performed on an Illumina HiSeq 4000 platform (Illumina, San Diego, CA) at the Novogene Bioinformatics Institute (Beijing, China) according to the manufacturer's instructions. The raw sequence data reported in this paper have been deposited in the Genome Sequence Archive (Wang et al., 2017) in the Beijing Institute of Genomics (BIG) Data Center (National Genomics Data Center Members and Partners, 2020), Chinese Academy of Sciences, under accession numbers CRA002550, publicly accessible at https:// bigd.big.ac.cn/gsa.

\section{Quality Analysis, Mapping, and Transcriptome Assembly}

Reads containing adapter, poly- $\mathrm{N}$ and low-quality reads in the raw data were removed to obtain clean reads. The proportion of bases with a paired basequality score more than 20 and 30 of the clean data and the percentage of base $\mathrm{G}$ and $\mathrm{C}$ in clean reads were calculated (Supplemental Table S4, https://doi .org/10.3168/jds.2020-19101). All downstream analyses were based on clean data with high quality. Reference bovine genome (ftp://ftp.ensembl.org/pub/release -89/fasta/bos_taurus/dna/) and gene model annotation files (ftp://ftp.ensembl.org/pub/release-89/gtf/ bos_taurus) were downloaded. Bowtie2 version 2.2.8 (https://sourceforge.net/projects/bowtie-bio/files/ bowtie $2 / 2.2 .8 /$ ) was used to build an index of the reference genome. HISAT2 version 2.0.4 (ftp://ftp.ccb .jhu.edu/pub/infphilo/hisat2/downloads) was used to align paired-end clean reads to the reference genome (Langmead and Salzberg, 2012). HISAT2 was run with "-rna-strandness RF," which is specific for pairend sequencing; other parameters were set as default. StringTie version 1.3.1 (http://ccb.jhu.edu/software/ stringtie/\#install) was used to assemble the mapped reads of each sample in a reference-based approach (Pertea et al., 2016). 


\section{Statistical Analysis}

Normality of the data was tested first. Then comparisons of DMI, NEFA, and blood triglycerides and BHB between Post-P and Pre-P were analyzed using the Proc Mixed model in SAS 9.4 (SAS Institute Inc., Cary, NC) with treatment and day as fixed effect, cows within treatment as random effect, and day as repeated effect.

Statistical analysis of sequencing data was performed with the effect of the peripartum assessed using the negative binomial generalized linear model in the DESeq2 package (1.26.0; http://www.bioconductor .org/packages/release/bioc/html/DESeq2.html) in $\mathrm{R}$ version 3.6.1 (https://www.r-project.org/; Love et al., 2014). P-values were adjusted using BenjaminiHochberg method. To obtain more reliable results, a strict threshold of adjusted $P$-values $\left(\boldsymbol{P}_{\text {adj }}\right)<0.01$ was set as the cut-off to identify differently expressed genes (DEG). Data quality assessment was performed by sample-to-sample distance visualization and principal component analysis using the dist and plotPCA function in DESeq2 (Supplemental Figures S1 and S2, https://doi.org/10.3168/jds.2020-19101). The density plot of the distribution of normalized read counts of each library is shown in Figure S3 (https://doi.org/10 .3168/jds.2020-19101).

\section{Bioinformatic Analyses}

Dynamic Impact Approach. The dynamic impact approach (DIA; https://dynamicimpactapproach .shinyapps.io/diarelease1/) was used to perform analysis of Kyoto Encyclopedia of Genes and Genomes (KEGG) pathways (Bionaz et al., 2012). The DIA estimates the magnitude of perturbation of a biological pathway by the "impact," and the overall direction of the perturbation is represented by the "flux" (or direction of the impact). Entrez Gene ID of detected transcripts were used as background. The data set including Entrez Gene ID, $P_{\text {adj }}$, expression ratio, and noncorrected $P$-value was uploaded. Adjusted $P$-value $<0.01$ and unadjusted $P$-value $<0.01$ between the 2 treatments were used as a cut-off. The top 30 impacted pathways were visualized using Pathview (https:// pathview.uncc.edu/; Luo et al., 2017). The data set of DEG was prepared and uploaded according to the Pathview tutorial.

Enrichment Analysis. Enrichment analysis of DEG using various databases, including KEGG pathways, Gene Ontology biological process, cellular components, and molecular function, was run by Database for Annotation, Visualization and Integrated Discovery (DAVID) version 6.7 (https://david.ncifcrf.gov/home .jsp; Huang et al., 2009). For this analysis, the Entrez Gene ID of all transcripts detected were used as background, and 3 separated data sets were analyzed: (1) upregulated DEG $\left(\log _{2}\right.$ fold change $\left.>0, P_{\text {adj }}<0.01\right)$ by Post-P versus Pre-P; $(2)$ downregulated DEG $\left(\log _{2}\right.$ fold change $\left.<0, P_{\text {adj }}<0.01\right)$ by Post-P versus Pre-P; and (3) both up- and downregulated DEG $\left(P_{\text {adj }}<0.01\right)$. Results were downloaded using both functional annotation chart and functional annotation clustering.

Preparation of the Data Set for Co-Expression Network Construction. Read counts of each gene and each sample were normalized by median normalization using EBSeq version 3.10 (http://www.bioconductor .org/packages/release/bioc/html/EBSeq.html) in the R package. After normalization, an integer 1 was added to all data to avoid values equal to zero. Then the matrix was transformed to a logarithmic matrix to standardize the variance (Dong et al., 2015). The correlation and correlation significance of every pair of DEG $\left(P_{\text {adj }}<\right.$ 0.01 ) were calculated using the logarithmic matrix of read counts. The calculation was performed using the $\mathrm{R}$ package psych (1.8.12; https://cran.r-project.org/ web/packages/psych/index.html). Pearson was chosen as the correlation method. The resulting table contains gene1 (source gene) and gene2 (target gene), the correlation values of the 2 genes, and the adjusted $P$-values were generated by the correction calculation. The generated table was filtered based on absolute correlation $>0.9$ and $P_{\text {adj }}<0.01$. For convenience, $P_{\text {adj }}$ values were converted to logarithmic base 10. To avoid problems with very low $P$-values, which are reported as 0 by the corr.test function in $\mathrm{R}$, we replaced 0 values with the smallest positive floating-point number interpreted as different from 0 in $\mathrm{R}$ configuration. Then, we generated the table containing the statistically significant correlations across the whole data set for every pair of DEG. Another R package, igraph (1.2.4.1; https:// igraph.org/r/), was used to calculate network statistics (degree and betweenness for each node) as described by Contreras-López et al. (2018). Those DEG with absolute correlation $>0.9$ were selected to construct the co-expression network.

Co-Expression Network Construction and Functional Annotation. The data set including correlation of DEG, degree and betweenness of the nodes, and $\log _{2}$ fold change of DEG were uploaded to Cytoscape version 3.7.2 (https://cytoscape.org/; Bindea et al., 2009). Gene symbols were set as the node identifiers. The correlation, correlation significance, degree and betweenness, and $\log 2$ fold change were mapped to the edge color, edge width, node size, and node fill color, respectively (Supplemental Figure S4, https:// doi.org/10.3168/jds.2020-19101). The co-expression network was clustered by the clusterMaker2 (https:/ 
/apps.cytoscape.org/apps/clustermaker2) plug-in of Cytoscape, using "community clustering" (GLay) with default options. Six major subnetworks (clusters) were generated (Supplemental Figure S5, https://doi.org/10 .3168/jds.2020-19101). The DEG within cluster 3 were, for the most part, upregulated, whereas in clusters 1 and 2, approximately half were upregulated (Supplemental Figure S5).

The functional annotation analysis of the clusters within the clustered network using the ClueGO 2.5.4 application (https://apps.cytoscape.org/apps/cluego), a plug-in of Cytoscape. We selected "GO Biological Process" with evidence code "All" and selected the option "Show only Pathways with $\mathrm{p}$..." and kept the default value of 0.05 . The first 3 subnetworks were successfully annotated with the enrichment significance $P$-value $\leq 0.05$. The visualized results were exported in PDF format and transformed to pictures using Adobe Illustrator CC 2019.

\section{RESULTS}

Principal component analysis revealed a clear separation with no overlap between Post-P and Pre-P samples, indicating that the transcriptome profiles of the liver in Pre-P and Post-P are distinct (Supplemental Figure S1). Results of hierarchical clustering analysis confirmed a large separation between the samples of the 2 periods (Supplemental Figure S2). The use of DESeq2 unveiled 2,674 DEG with 1,475 upregulated and 1,199 downregulated (Figure 1, $P_{\text {adj }}<0.01$ ).

\section{DMI and Serum Metabolites}

As shown in Table 1, from Pre-P to Post-P, the DMI and blood BHB and NEFA contents increased 1.5- and 7.7-fold, respectively $(P<0.0001)$, and the concentration of triglycerides in serum decreased 6.5 -fold $(P<$ $0.0001)$.

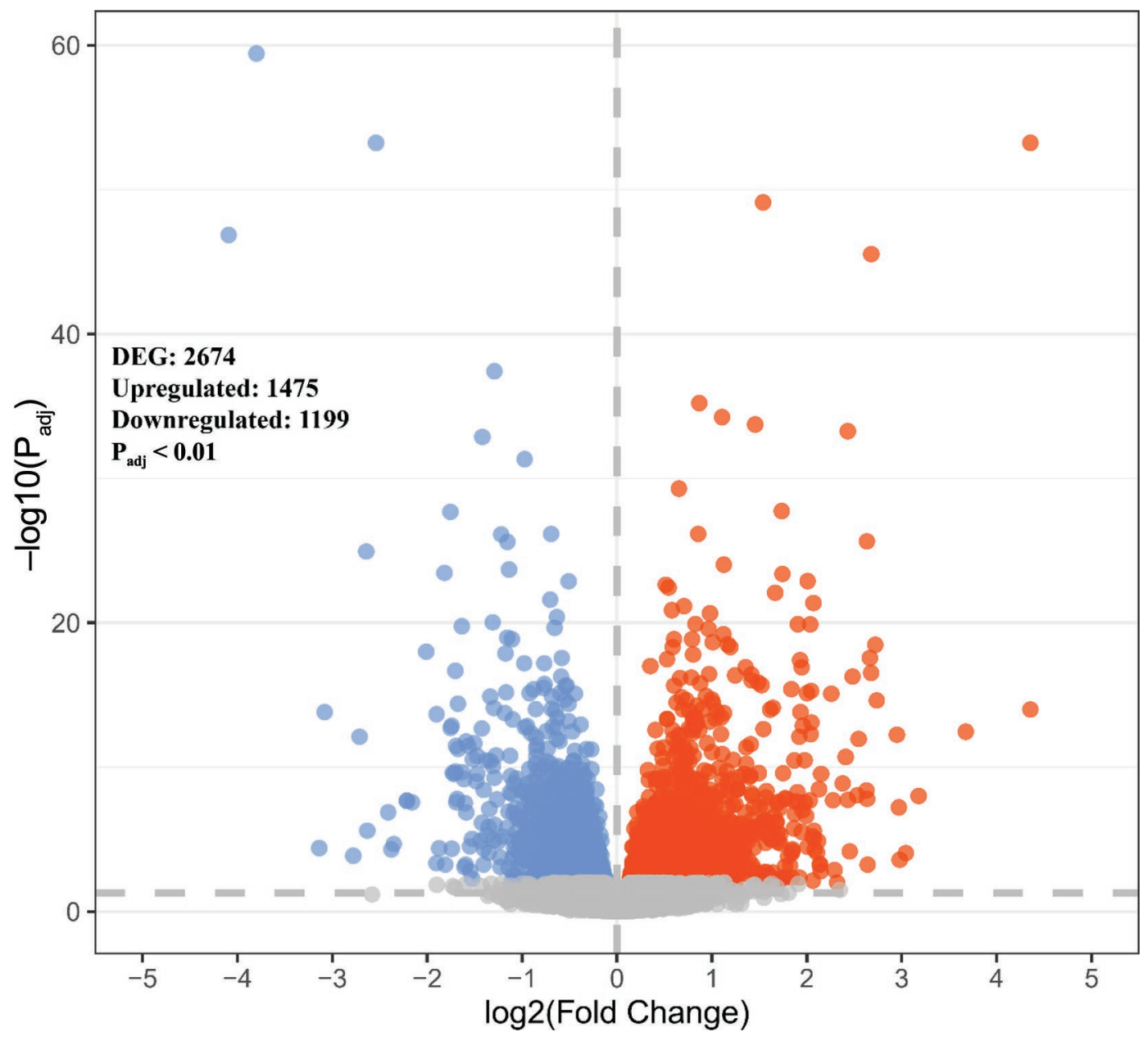

Figure 1. Volcano plot for the differently expressed genes (DEG) of liver tissue of postpartum (Post-P) compared with prepartum (Pre-P). Red points represent upregulated DEG. Blue points represent downregulated DEG. Gray points represent genes that were not significantly upor downregulated. The cut-off used for DEG was adjusted $P$-value $\left(P_{\text {adj }}\right)<0.01$. 


\section{DIA Analysis Reveals Overall Increased Metabolism and Cell Cycle but Inhibited Xenobiotic Metabolism}

A summary of the KEGG pathways impacted by the transcriptome changes in Post-P versus Pre-P in liver tissue, as estimated by the DIA, is shown in Figure 2. All the main categories of KEGG pathways were impacted to different extents, and most were activated. The metabolism category, followed by cellular processes, were the most impacted main categories of KEGG pathways. Within the main category of metabolism pathways, almost all subcategories of pathways were activated to different extents, except for the subcategory of xenobiotics biodegradation and metabolism, which was inhibited. The impact and flux of the most impacted pathways in each of the categories of KEGG pathways are shown in Figure 3, and details for all pathways are available in Supplemental File S1 (https: //doi.org/10.3168/jds.2020-19101). The importance of metabolic-related pathways is highlighted by the fact that, among the 30 most affected pathways, 16 (>50\%) were related to metabolism, followed by organismal systems (23\%; Supplemental Figure S6 and Supplemental File S1, https://doi.org/10.3168/jds.2020-19101).

Among the metabolic-related pathways, the ones related to carbohydrates, lipid, amino acids, vitamins, and biosynthesis of secondary metabolites were the most impacted and most activated in Post-P compared with Pre-P (Figure 2). Among carbohydrate-related pathways, the most impacted and activated were those related to utilization and production of glucose, including the propanoate metabolism pathway, for utilization of propionic acid (Figure 3). Among the lipid-related pathways highly activated were those related to fatty acid catabolism, along with activation of fatty acid synthesis and production of triglycerides (i.e., glycerolipid metabolism; Figure 3). Highly impacted but inhibited were the steroid hormone biosynthesis and linoleic acid metabolism pathways. All amino acid metabolism-related pathways were activated, with glutathione metabolism as the top activated pathway, followed by pathways associated with the metabolism of Arg, Pro, Cys, Met, and His (Figure 3). Among pathways related to the metabolism of cofactors and vitamins, the riboflavin metabolism pathway was highly activated, whereas other highly impacted pathways in this category were inhibited, such as vitamin B6, retinol, and thiamine metabolism (Figure 3). Other impacted pathways related to metabolism were caffeine metabolism, highly activated in the liver from Post-P to Pre-P cows, and drug metabolism-cytochrome P450, highly inhibited.

Few genetic information processing pathways were highly impacted, all related to the synthesis of proteins, especially in the endoplasmic reticulum that are then exported (Figure 3). Among the pathways associated with cellular processes, peroxisome (highly activated) and phagosome (highly inhibited) were the most important pathways associated with transport and catabolism. The high impact and activation of the cell cycle pathway and inhibition of apoptosis and P53 signaling pathways indicated an increase in cell proliferation in the liver (Figure 3).

Several signaling pathways relating to environmental information processing were highly activated, including AMPK, Hippo, ErbB, and Wnt signaling pathways, with the phosphatidylinositol signaling system being inhibited (Figure 3) were highly impacted in the hepatic adaptation to the peripartum. The 3 most impacted and activated signaling pathways were PPAR, adipokines, and glucagon signaling pathways, all part of the organismal systems (Figure 3 ).

Several pathways related to the immune system were activated in the liver for Pre-P, with IL17 and RIG-like receptor being among the most activated, but with important additional activation for toll-like receptor and TNF signaling (Figure 3). Pathways related to the digestive system were, for the most part, inhibited in the liver from Pre-P to Post-P (Figure 2 and Supplemental File S1); however, the digestion and absorption of fat and vitamins were highly activated, but the digestion and absorption of carbohydrates and minerals were overall inhibited (Figure 3).

Table 1. Comparison of DMI, nonesterified fatty acids (NEFA), blood triglycerides, and BHB of cows prepartum (Pre-P) and postpartum (Post-P)

\begin{tabular}{|c|c|c|c|c|c|}
\hline Item & Pre-P & Post-P & SEM & \multicolumn{2}{|c|}{$P$-value } \\
\hline $\mathrm{DMI}(\mathrm{kg} / \mathrm{d})$ & 12.8 & 19.1 & 0.097 & $<0.0001$ & $<0.0001$ \\
\hline NEFA $(\mathrm{m} M)$ & 0.11 & 0.85 & 0.033 & $<0.0001$ & $<0.0001$ \\
\hline $\mathrm{BHB}(\mathrm{m} M)$ & 0.76 & 0.79 & 0.029 & 0.7265 & $<0.0001$ \\
\hline Triglycerides $(\mathrm{m} M)$ & 0.13 & 0.02 & 0.009 & $<0.0001$ & 0.5860 \\
\hline
\end{tabular}

${ }^{1}$ Values are \pm SD. 


\begin{tabular}{|c|c|}
\hline \multirow{2}{*}{$\begin{array}{l}\text { Category } \\
\text { 1. Metabolism }\end{array}$} & Post-P vs. Pre-P \\
\hline & \\
\hline \multicolumn{2}{|l|}{1.0 Global and overview maps } \\
\hline \multicolumn{2}{|l|}{ 1.1 Carbohydrate Metabolism } \\
\hline \multicolumn{2}{|l|}{ 1.2 Energy Metabolism } \\
\hline \multicolumn{2}{|l|}{ 1.3 Lipid Metabolism } \\
\hline \multicolumn{2}{|l|}{ 1.4 Nucleotide Metabolism } \\
\hline \multicolumn{2}{|l|}{ 1.5 Amino Acid Metabolism } \\
\hline \multicolumn{2}{|l|}{ 1.6 Metabolism of Other Amino Acids } \\
\hline \multicolumn{2}{|l|}{ 1.7 Glycan Biosynthesis and Metabolism } \\
\hline \multicolumn{2}{|l|}{ 1.8 Metabolism of Cofactors and Vitamins } \\
\hline \multicolumn{2}{|l|}{ 1.9 Metabolism of Terpenoids and Polyketides } \\
\hline \\
\hline \multicolumn{2}{|l|}{ 1.11 Xenobiotics Biodegradation and Metabolism } \\
\hline \multicolumn{2}{|l|}{ 2. Genetic Information Processing } \\
\hline \multicolumn{2}{|l|}{ 2.1 Transcription } \\
\hline \multicolumn{2}{|l|}{ 2.2 Translation } \\
\hline \multirow{2}{*}{\multicolumn{2}{|c|}{$\begin{array}{l}\text { 2.3 Folding, Sorting and Degradation } \\
\text { 2.4 Replication and Repair }\end{array}$}} \\
\hline & \\
\hline \multicolumn{2}{|l|}{ 3. Environmental Information Processing } \\
\hline \multicolumn{2}{|l|}{ 3.1 Membrane transport } \\
\hline \multicolumn{2}{|l|}{ 3.2 Signal Transduction } \\
\hline \multicolumn{2}{|l|}{ 3.3 Signaling Molecules and Interaction } \\
\hline \multicolumn{2}{|l|}{ 4. Cellular Processes } \\
\hline \multicolumn{2}{|l|}{ 4.1 Transport and Catabolism } \\
\hline \multicolumn{2}{|l|}{ 4.2 Cell Motility } \\
\hline \multicolumn{2}{|l|}{ 4.3 Cell Growth and Death } \\
\hline \multicolumn{2}{|l|}{ 4.4 Cell Communication } \\
\hline \multicolumn{2}{|l|}{ 4.5 Cell Motility } \\
\hline 5. Organismal Systems & \\
\hline 5.1 Immune System & \\
\hline 5.2 Endocrine System & \\
\hline 5.3 Circulatory System & \\
\hline 5.4 Digestive System & \\
\hline 5.5 Excretory System & \\
\hline 5.6 Nervous System & \\
\hline 5.7 Sensory System & \\
\hline 5.8 Development & \\
\hline 5.9 Aging & \\
\hline 5.10 Environmental Adaptation & \\
\hline Impact $=0$ & 200 \\
\hline Flux $=-100 \quad-50$ & 100 \\
\hline
\end{tabular}

Figure 2. Summary of the main categories and subcategories of Kyoto Encyclopedia of Genes and Genomes pathways as results of the transcriptomic effect on liver tissue of postpartum (Post-P) versus prepartum (Pre-P) dairy cows, as analyzed via the Dynamic Impact Approach. On the right are the bars denoting the overall impact (in blue) and the shade denoting the effect on the pathway (from green $=$ inhibited to red $=$ activated). The darker the color, the greater the activation or inhibition of the pathway. 

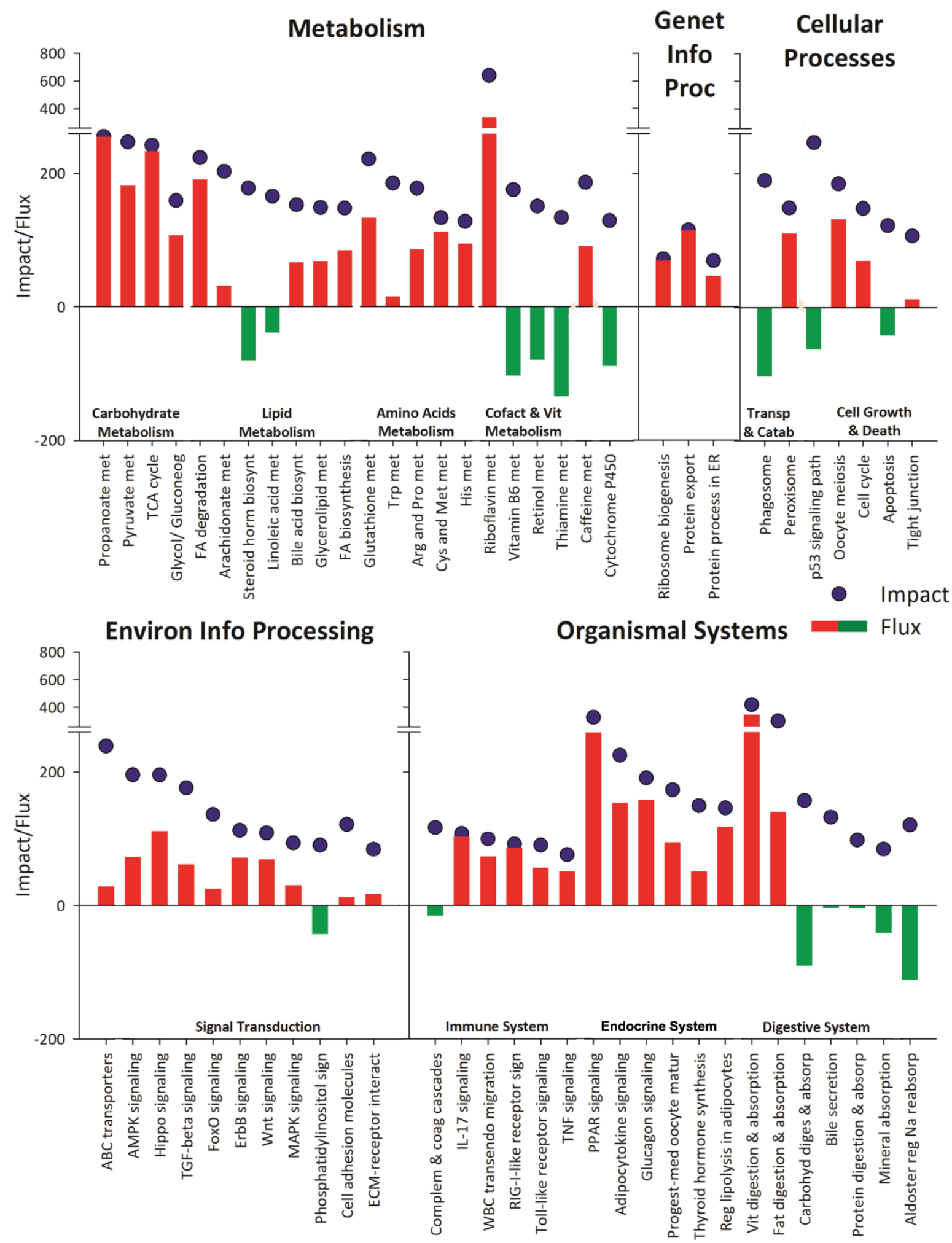

Figure 3. Most impacted pathways in each of the 5 main category of Kyoto Encyclopedia of Genes and Genomes pathways (the category of pathway "Human Disease" is not reported) in the liver of postpartum (Post-P) versus prepartum (Pre-P) pregnancy of dairy cows to 2 wk into lactation, as revealed by Dynamic Impact Approach analysis of RNA sequencing data. In the y-axis is reported the magnitude of the impact and the direction of the impact (or flux; i.e., positive or red = activated, and negative or green = inhibited). Genet Info Proc $=$ genetic information processing; Environ Info Processing $=$ environment information processing; TCA = tricarboxylic acid; FA $=$ fatty acid; cofact $=$ cofactor; vit $=$ vitamin; transp = transportation; catab = catabolism; complem $=$ complementary; coag $=$ coagulation; reg $=$ regulation; absorp $=$ absorption . 


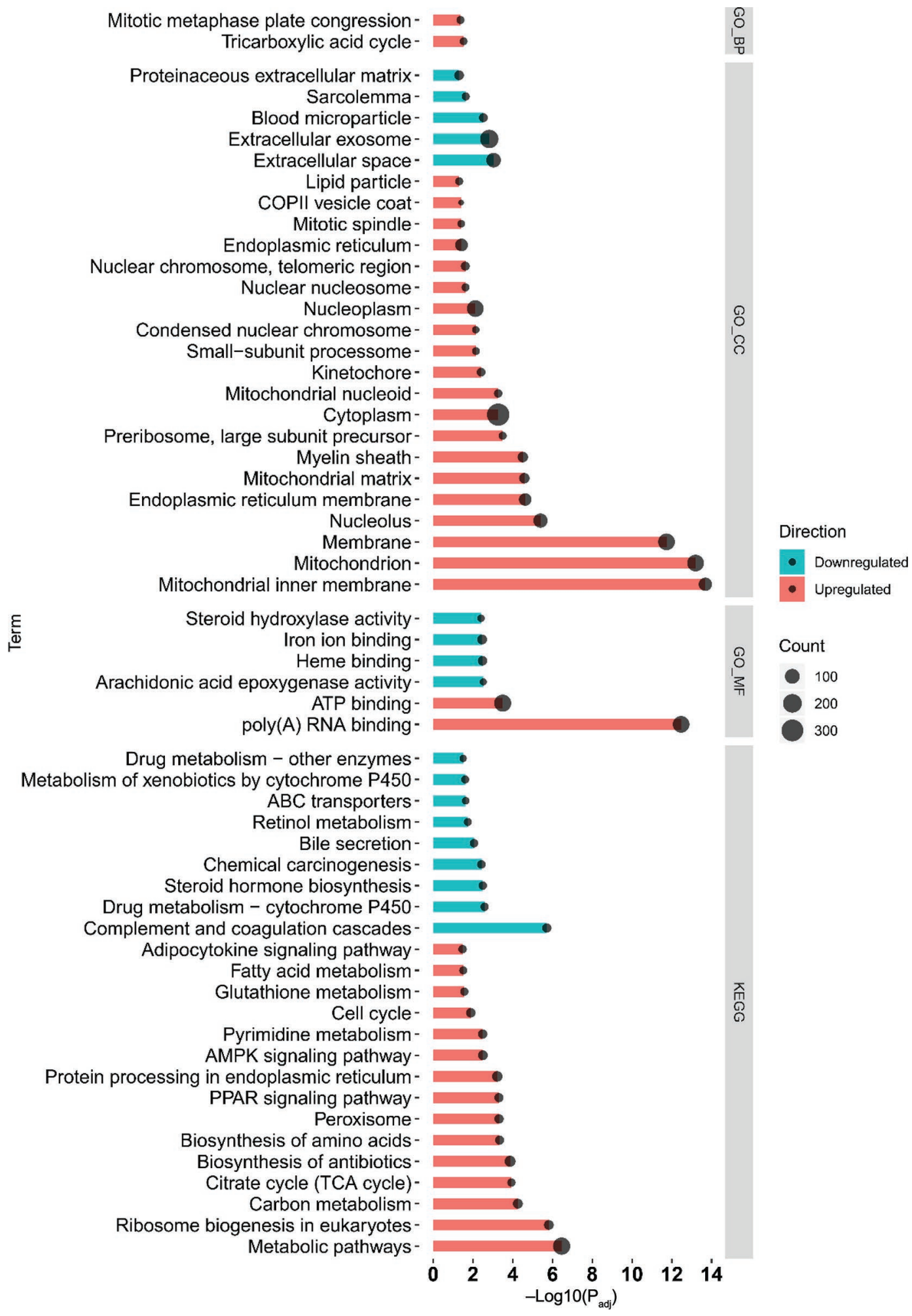

Figure 4. Significantly enriched Gene Ontology (GO; BP = biological process; $\mathrm{CC}=$ cellular component; $\mathrm{MF}=$ molecular function $)$ and Kyoto Encyclopedia of Genes and Genomes (KEGG) pathways revealed by Database for Annotation, Visualization and Integrated Discovery analysis of the transcripts upregulated (red) or downregulated (blue) in liver tissue of postpartum versus prepartum cows. Vertical axis shows the terms; horizonal axis shows the transformed false discovery rate $\left[-\log _{10}\right.$ adjusted $P$-value $\left.\left(P_{\text {adj }}\right)\right]$. TCA $=$ tricarboxylic acid. 


\section{Enrichment Analysis Confirms Importance of Metabolism and Cell Division}

Most of the enriched terms in DEG between Post-P and Pre-P liver of dairy cows in our study, as revealed by DAVID, were associated with upregulated compared with downregulated DEG (Figure 4 and Supplemental File S2, https://doi.org/10.3168/jds.2020-19101). Upregulated DEG were enriched with GO Biological Process associated with the tricarboxylic acid (TCA) cycle and cell division. The most enriched cellular component terms were related to mitochondria and endoplasmic reticulum, whereas, among downregulated DEG, terms related to extracellular space and exosomes were the most enriched. Terms related to transcription and ATP were the most enriched molecular functions among upregulated DEG, and terms related to use of arachidonic acid and steroid were the most enriched among downregulated DEG.

The DAVID analysis revealed that several KEGG pathways were enriched in DEG between Post-P and Pre-P livers of dairy cows. Most of the same pathways revealed to be impacted by DIA were enriched in DAVID (Figure 4 and Supplemental File S2). Upregulated DEG were enriched with KEGG pathways associated with metabolism (specifically TCA cycle and fatty acid and amino acid metabolism), cell cycle, and protein synthesis. Among signaling pathways, DAVID revealed enrichment of AMPK, PPAR, and adipocytokine signaling pathways among upregulated DEG. Drug metabolism, steroid hormone biosynthesis, retinol metabolism, bile secretion, and complement and coagulation cascades were among the most enriched KEGG pathways in downregulated DEG.

\section{Co-Expression Network Analysis Reveals High Coordination Between Cell Division and Metabolism}

For the first cluster within the co-expression network, 2 major functionally grouped annotation networks were revealed: RNA modification and oxidative phosphorylation (Supplemental Figure S7, https://doi.org/ 10.3168/jds.2020-19101). The downregulated DEG in cluster 1 were mainly associated with ensheathment of neurons, activation of GTPase activity, neuroblast proliferation, and pathway-restricted SMAD protein phosphorylation (Supplemental Figure S8, https://doi .org/10.3168/jds.2020-19101), whereas the upregulated DEG were associated mainly with RNA modification, ncRNA processing, oxidative phosphorylation, protein import into mitochondrial matrix, and mitochondrial gene expression (Supplemental Figure S9, https://doi .org/10.3168/jds.2020-19101). The DEG in the second cluster were mainly enriched with intestinal cholesterol absorption, intestinal lipid absorption, regulation of insulin-like growth factor receptor signaling pathway, and response to insulin (Supplemental Figure S10, https:/ /doi.org/10.3168/jds.2020-19101). The downregulated DEG of cluster 2 were mainly enriched with positive regulation of protein import in nucleus and cholesterol efflux (Supplemental Figure S11, https://doi.org/10 .3168/jds.2020-19101), whereas upregulated DEG were mainly enriched with fatty acid metabolic process and long-chain fatty acid transport (Supplemental Figure S12, https://doi.org/10.3168/jds.2020-19101). For the third cluster, which consisted mainly of upregulated DEG, high enrichment of terms associated with cell division (such as mitotic cell cycle process and regulation of chromosome segregation), metabolism (such as positive regulation of ATP metabolic process), and transport (such as intestinal cholesterol absorption) were detected in tightly connected DEG (Supplemental Figure S13, https://doi.org/10.3168/jds.2020-19101).

\section{DISCUSSION}

The liver is a critical hub for numerous physiological processes. Among these, processing, partitioning, and metabolism of macronutrients are the liver's most critical functions (Nordlie et al., 1999; Trefts et al., 2017). During the peripartum period, the ability of the liver to face increased metabolic challenges is a prerequisite for cows' successful adaptation to lactation without development of health disorders (Graber et al., 2010; Ha et al., 2017). Therefore, several studies have been carried out to improve understanding of the biological changes of the liver during the peripartum, using high-throughput transcriptomic techniques (Loor et al., 2005; Ha et al., 2017; Qin et al., 2018).

Prior studies have revealed a relatively mild transcriptomic change of the liver of dairy cows during the peripartum. In the study by Loor et al. (2005), where liver samples from 7 time points from -65 to $+49 \mathrm{~d}$ relative to parturition were collected from 5 cows, only 62 DEG ( $\sim 1 \%$ of the measured transcripts), using a liberal 0.2 false discovery rate (FDR), were detected. The same data set, analyzed using a more robust statistical approach, uncovered that up to $20 \%$ of the measured genes were affected by the peripartum in the liver (Bionaz and Loor, 2012). A work by Qin et al. (2018) detected change of 654 DEG $(\mathrm{FDR}=0.05)$ from -8 to $9 \mathrm{~d}$ relative to parturition in 16 Holstein cows (with 2 different diets prepartum) using an Affymetrix array (Affymetrix Inc., Santa Clara, CA), corresponding to $<5 \%$ of unique measured genes. In the work of Ha et al. (2017), 1,000 DEG were detected in the liver of 6 cows, with FDR $=0.05$, out of 10,000 measured genes, corresponding to $10 \%$ of the measure transcriptome. 
Our data, with the revelation of $>2,500$ DEG $(15.7 \%$ of detected unique genes) appears to confirm that the use of RNAseq, in combination with large numbers of cows, can provide a more in-depth approach to study the adaptation of the liver to lactation.

\section{Metabolism Is the Major Adaptation of the Liver During the Periparturient Period}

The overall activation of metabolism in the liver, as revealed by the transcriptomic analysis in the present study, is in accordance with the major role of the liver in metabolism of macronutrients, both in monogastric animals (Trefts et al., 2017) and in ruminants (Bergman et al., 1971; Grum et al., 1996; Drackley, 1999). It is also in agreement with prior physiological data, demonstrating that the metabolic activity of the liver doubles from around $10 \mathrm{~d}$ prepartum to $10 \mathrm{~d}$ postpartum in dairy cows, due also to a large increase in blood flow and oxygenation (Drackley et al., 2001). Prior transcriptomics data also highlighted metabolism as the predominant functional adaptation of the liver in transition cows (Ha et al., 2017). The increased hepatic metabolism is also enhanced by inadequate voluntary DMI of fresh cows, which does not allow them to satisfy the increased nutrient demand (Bertoni et al., 2009), leading to a physiological state of negative energy and nutrient imbalance. A cascade of metabolic adaptive processes follows, including increased hepatic gluconeogenesis and protein synthesis, adipose fat mobilization with increased circulating NEFA, and peripheral mobilization of amino acids that require larger ureagenesis (Bell, 1995). In all of those processes, the liver plays a central role (Drackley et al., 2005).

Our data appear to provide further evidence of the physiological adaptation of the liver, as NEFA increased and triglycerides decreased from Pre-P to Post-P. Our data are consistent with prior studies (Kessler et al., 2014; Davis et al., 2019), including those showing increased gluconeogenesis (Greenfield et al., 2000; Reynolds et al., 2003) and utilization of NEFA via oxidation and re-esterification (Loor et al., 2005) by the liver during the peripartum.

In addition, we note that vitamin B6 and thiamine metabolism in liver were decreased in Post-P compared with Pre-P in this study. However, similar results have rarely been revealed by previous studies. Preynat et al. (2010) suggested that liver concentrations of folates and vitamin B12 were increased by their respective supplements via intramuscular injections. Similar results were also revealed by Akins et al. (2013). The results of Graulet et al. (2007) showed that dietary supplements of folic acid and vitamin B12 given from 3 wk before to 8 wk after calving increased the plasma and liver concentrations of folates and B12. In the present study, to meet the vitamin requirement of Pre-P cows with low DMI, vitamin B complex content in the close-up cow diet was 2-fold higher than in the fresh cow diet (Supplemental Table S2, https://doi.org/10 $.3168 /$ jds.2020-19101). Thus, the decreased vitamin B6 and thiamine metabolism in the liver of Post-P compared with Pre-P cows can partly be explained by the lower vitamin $\mathrm{B}$ consumption by Post-P cows than Pre-P cows.

\section{Increased Fatty Acid Metabolism Is Regulated by PPAR and Adipocytokines}

Our data clearly indicate a strong increase in expression of genes involved with fatty acid oxidation. As previously argued (Bionaz et al., 2013) and as indicated by the present data, the central player in this adaptation appears to be the PPAR signaling. A detailed visualization of the PPAR signaling KEGG pathways revealed increase in expression of most of the genes in that pathway (Figure 5). However, there are 3 PPAR isotypes, with PPARA as the most abundantly expressed in the liver of dairy cows (Bionaz et al., 2013), which was confirmed in the present data (see Supplemental File S3, https://doi.org/10.3168/jds.2020-19101). Contrary to the data from Loor et al. (2005), PPARA was downregulated in our study $\left(1.2\right.$-fold, $\left.P_{\text {adj }}=0.02\right)$, with no change for the other PPAR isotypes. Our data are similar to those from $\mathrm{Ha}$ et al. (2017; 1.4-fold downregulated, $\left.P_{\text {adj }}=0.001\right)$, with no effect on the other 2 PPAR isotypes. Proteome results from Schäff et al. (2012) also indicated an obvious decrease of PPARA and no significant change in abundance of PPARG from prepartum to postpartum. Others have found no change in transcription of PPARA in the liver of peripartum cows (Kessler et al., 2014). The downregulation or lack of change in expression of PPARA, with a higher change in putative downstream target genes, appears to be a contradiction; however, as previously argued (Bionaz et al., 2015), the activity of a transcription factor is not dependent on its transcription. The increased activation of PPAR in the liver of transition cows is partly explained by increased NEFA, as previously argued (Bionaz et al., 2013) and recently demonstrated in vitro (Busato and Bionaz, 2020). As Figure 5 shows, it appears that more putative downstream targets of PPARD were affected compared with the putative downstream targets of PPARA. Recent data generated in vitro revealed that PPARD responded to NEFA in bovine hepatocytes, but PPARA did not (Busato and Bionaz, 2020). The high importance of PPAR during the transition, as observed in the present manuscript, or during the response to changes in the energy level 


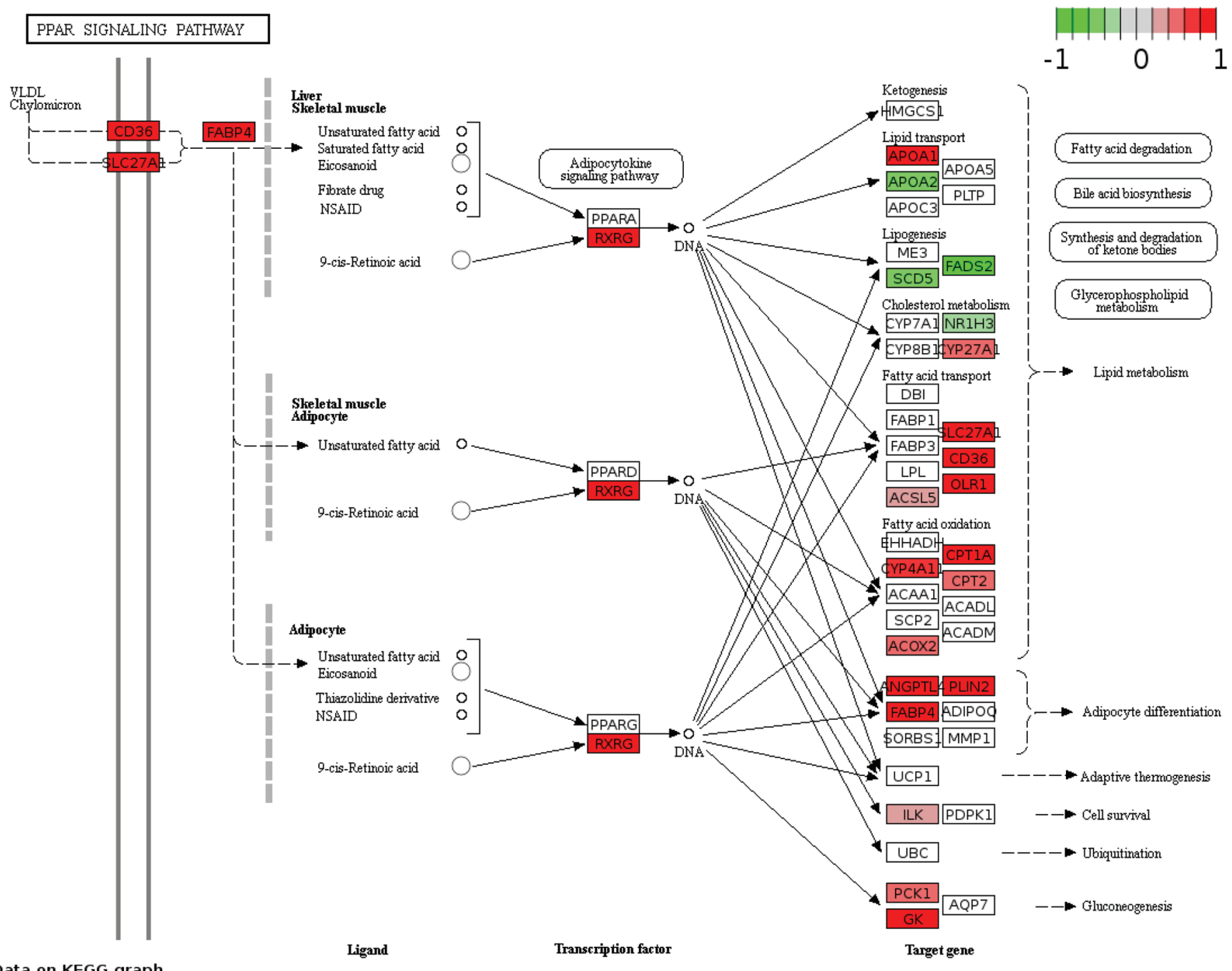

Data on KEGG graph Rendered by Pathview

Figure 5. Differently expressed genes (DEG) of postpartum versus prepartum dairy cows in the Kyoto Encyclopedia of Genes and Genomes (KEGG) PPAR signaling pathway. Changes of direction of DEG are mapped by colors. Green denotes downregulated DEG; red indicates upregulated DEG. VLDL = very low density lipoprotein; NSAID = nonsteroidal anti-inflammatory drug.

in the diet (Loor et al., 2007; Bionaz and Loor, 2012; McCabe et al., 2012), further supports the importance of PPAR in the adaptation of the liver to the transition period (Bionaz et al., 2013).

The large impact and activation in DIA and enrichment in DAVID of the adipocytokine pathway (Figure 3 and Figure 4), which is consistent with the finding of Ha et al. (2017), suggest an important role of adipose tissue in controlling the adaptation of the liver through the release of adipocytokines such as adiponectin and leptin that, by binding to specific receptors in the liver, can affect PPAR signaling via activation of AMPK signaling (induced in our study, Figure 3 and Figure 4), as observed in monogastric species (Cao, 2014). Thus, in addition to NEFA, adipocytokines released from adipose tissue also appear to play an important regulatory role in the liver of peripartum cows.

When NEFA cannot be oxidized to carbon dioxide or transformed to ketone bodies completely, they are reesterified into triglycerides, and fatty liver may develop (Bobe et al., 2004). In the present study, pathways associated with the synthesis of lipids, including fatty acids and glycerolipids, were induced in Post-P versus Pre-P liver (i.e., fatty acid biosynthesis and glycerolipids metabolism, Figure 3), indicating an increased capacity of the liver to synthesize and accumulate tri- 
glycerides. Accumulation of triglycerides in the liver is typical of early-postpartum cows (Drackley, 1999), and our data indicate that this process is regulated at the transcriptomic level, providing support for a previously proposed model (Loor et al., 2005).

\section{Increase in Early Postpartum Hepatic Proliferation}

Regarding the role of lipid metabolism, all the bioinformatic tools used to analyze our data set revealed an important activation of cell proliferation, supported by induction of the cell cycle and inhibition of apoptosis. In addition, the Wnt signaling pathway and ErbB signaling pathway, which are involved in cell growth (Acebron et al., 2014) and proliferation (Marmor et al., 2004), were also induced in Post-P versus Pre-P cows. The hippo signaling pathway, which is the upstream pathway of the Wnt signaling pathway, was also activated in Post-P compared with Pre-P. The hippo signaling pathway negatively regulates cell cycle and cell death by inhibiting the Wnt signaling pathway (Huang et al., 2005; Heallen et al., 2011). Overall, the results of the present study implied an activated cell proliferation in liver during the peripartum, which is consistent with the previously observed $9 \%$ increased weight of the liver from $1 \mathrm{wk}$ before calving to $3 \mathrm{wk}$ postpartum in dairy cows (Reynolds et al., 2004). The higher cell cycle despite a modest increase in liver size might also be due to a response of the liver to increased damage in the early postpartum, as suggested by the previously observed increase of liver enzymes in plasma of early postpartum cows (Shahzad et al., 2014a). This is likely partly due to accumulation of triglycerides (Shahzad et al., 2014a).

\section{Carbohydrate Metabolism in the Liver}

Our data indicated an important transcriptomic adaptation to glucose metabolism in the liver of Pre-P cows. Propanoate metabolism was the most impacted pathways and was highly activated (Figure 3), supporting the observed increase in the capacity of the liver to convert propionate into glucose in early postpartum versus prepartum cows (Drackley et al., 2001). Detailed visualizations of the other most impacted pathways related to glucose metabolism are shown in Figures 6, 7, and 8. From the pathways it is obvious that many energy substrates flowed into the TCA cycle, indicating activation of energy metabolism in the liver. However, the highly impacted and activated TCA cycle might be also associated with the greater utilization of amino acids for gluconeogenesis, due to the insufficient availability of propionate due to insufficient feed intake, as previously reviewed (Drackley et al., 2001). As support, results from our DIA indicated that most amino acid metabolic pathways were induced during Pre-P in the liver of dairy cows (Figure 3). Reynolds et al. (2003) demonstrated an increased contribution of alanine and glutamine to gluconeogenesis in the liver of postpartum versus prepartum cows. In the present study, we found that the pathways associated with alanine and glutamine metabolism were induced according to DIA but were not among the most impacted; however, amino acid metabolic pathways were not important according to the enrichment tools used. Overall, our data based on DIA suggest a likely increased contribution of amino acid to gluconeogenesis in Post-P versus Pre-P cows.

The increasing importance of gluconeogenesis in the liver of peripartum cows in our study is also supported by the upregulation of the genes encoding the key enzymes for this pathway: G6PC, $P C K 1$, and $P C$ (Greenfield et al., 2000; $P_{\text {adj }}<0.01$; Supplemental File S3, https://doi.org/10.3168/jds.2020-19101). However, both PGM1 and PGM5, 2 critical genes coding for phosphoglucomutase isoforms, were downregulated (Figure 8 and Supplemental File S3). The products of these genes catalyze the reversible interconversion of glucose 1-phosphate (toward glucose synthesis) and glucose 6-phosphate (toward glycolysis). Jin et al. (2018) demonstrated that decreased expression of PGM1 can prevent glycogenesis and leads to more glucose toward glycolysis. Furthermore, several genes related to glucose transport (SLC2A2, SLC2A4, and SLC2A5) were downregulated in the liver during the transition from pregnancy to lactation (Supplemental File S3). Among these transporters, only the transporter coded by $S L$ C2A2 is involved in the release of glucose synthesized by gluconeogenesis in the liver into the blood (Zhao and Keating, 2007). The positive correlation between SLC2A2 and FoxO1 was demonstrated by Kinoshita et al. (2016), but FoxO1 was not detected in the present study. Mice lacking Slc2a2 do not have impaired gluconeogenesis, indicating that glucose might be secreted by the liver via facilitated diffusion-independent mechanisms or other transporters (Karim et al., 2012). The absorption of dietary-derived glucose by the liver is very important in monogastric animals (Karim et al., 2012); however, the importance is low in ruminants, owing to the negligible amount of absorbed glucose from the diet. Despite this, the downregulation of the other glucose transporters may suggest that the glucose absorption of liver from blood was decreased in Post-P compared with Pre-P cows. The reason for such observation is unclear; however, it is possible that the liver spared blood glucose for other organs, chiefly the mammary gland. 
Overall, our data strongly support an activation of gluconeogenesis in Post-P versus Pre-P cows. However, the reason for the downregulation of PGM genes and SLC2A2 and other glucose transporters are unclear and warrant further evaluation.

\section{Increased Protein Synthesis in the Liver and the Inflammatory Response}

The liver is a protein synthetic organ that is responsible for 85 to $90 \%$ of circulating proteins (Trefts et

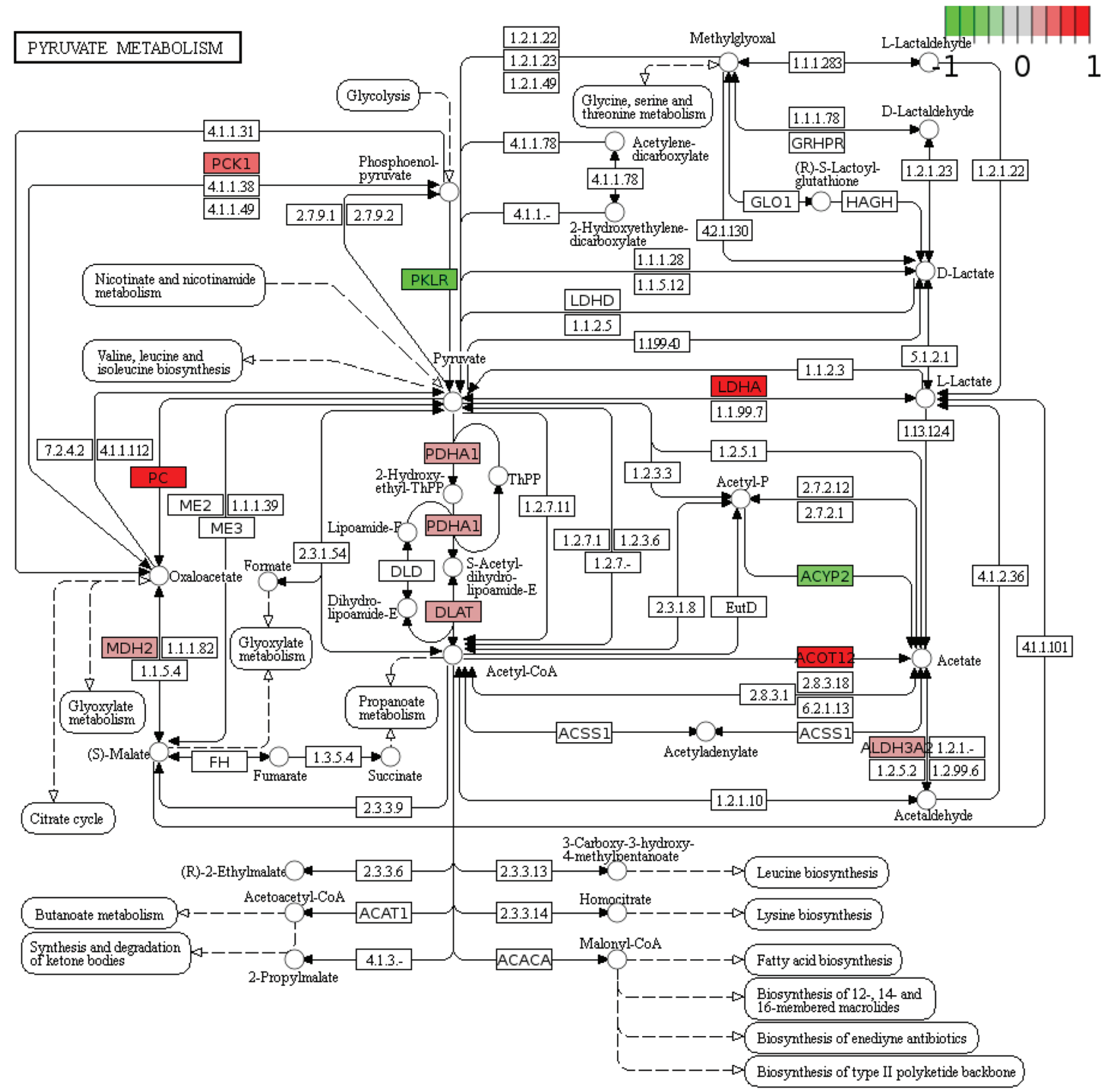

\section{Data on KEGG graph}

Rendered by Pathview

Figure 6. Differently expressed genes (DEG) of postpartum versus prepartum dairy cows in the Kyoto Encyclopedia of Genes and Genomes (KEGG) pyruvate metabolism pathway. Changes of direction of DEG are mapped by colors. Green indicates genes were downregulated. Red indicates genes were upregulated. $\mathrm{PC}=$ pyruvate carboxylase; PCK1 = phosphoenolpyruvate carboxykinase $1 ; \mathrm{MDH} 2=$ malate dehydrogenase $2 ;$ LDHA = lactate dehydrogenase A. 
al., 2017). The bioinformatic analysis of our RNAseq results do not support an overall increase in the induction of protein synthesis in the liver of Post-P versus Pre-P cows (e.g., mTOR pathways were not activated) but clearly support an increase of synthesis of proteins in the endoplasmic reticulum and their export. The major protein synthesized and secreted by the liver is albumin, which is also a negative acute-phase protein. The level of albumin is usually decreased around calving in dairy cows due to inflammatory-like conditions (Bionaz et al., 2007; Bertoni et al., 2008; Bradford et al., 2015). The transcription of albumin, as well as other negative acute phase-proteins such as paraoxonase 1 (coded by the PON1 gene), was downregulated in our experiment (Supplemental File S3, https://doi.org/10
$.3168 / j d s .2020-19101)$ indicating a possible response to inflammatory-like conditions.

The adaptation of the liver transcriptome from Pre-P to Post-P in our study is also supported by the increased transcription of few positive acute-phase proteins, such as SAA (SAA3) and CRP (CRP; Supplemental File S3, https://doi.org/10.3168/jds.2020-19101). Further support is provided by the important impact and induction of several proinflammatory signaling pathways revealed by DIA, including the pathway associated with the proinflammatory IL-17 (Amatya et al., 2017), TNF-A, and toll-like receptors (Aoyama et al., 2010). Activation of several of the same pathways was also detected in a prior experiment where Escherichia coli was infused into the mammary gland of cows, inducing a large in-

CITRATE CYCLE (TCA CYCLE)
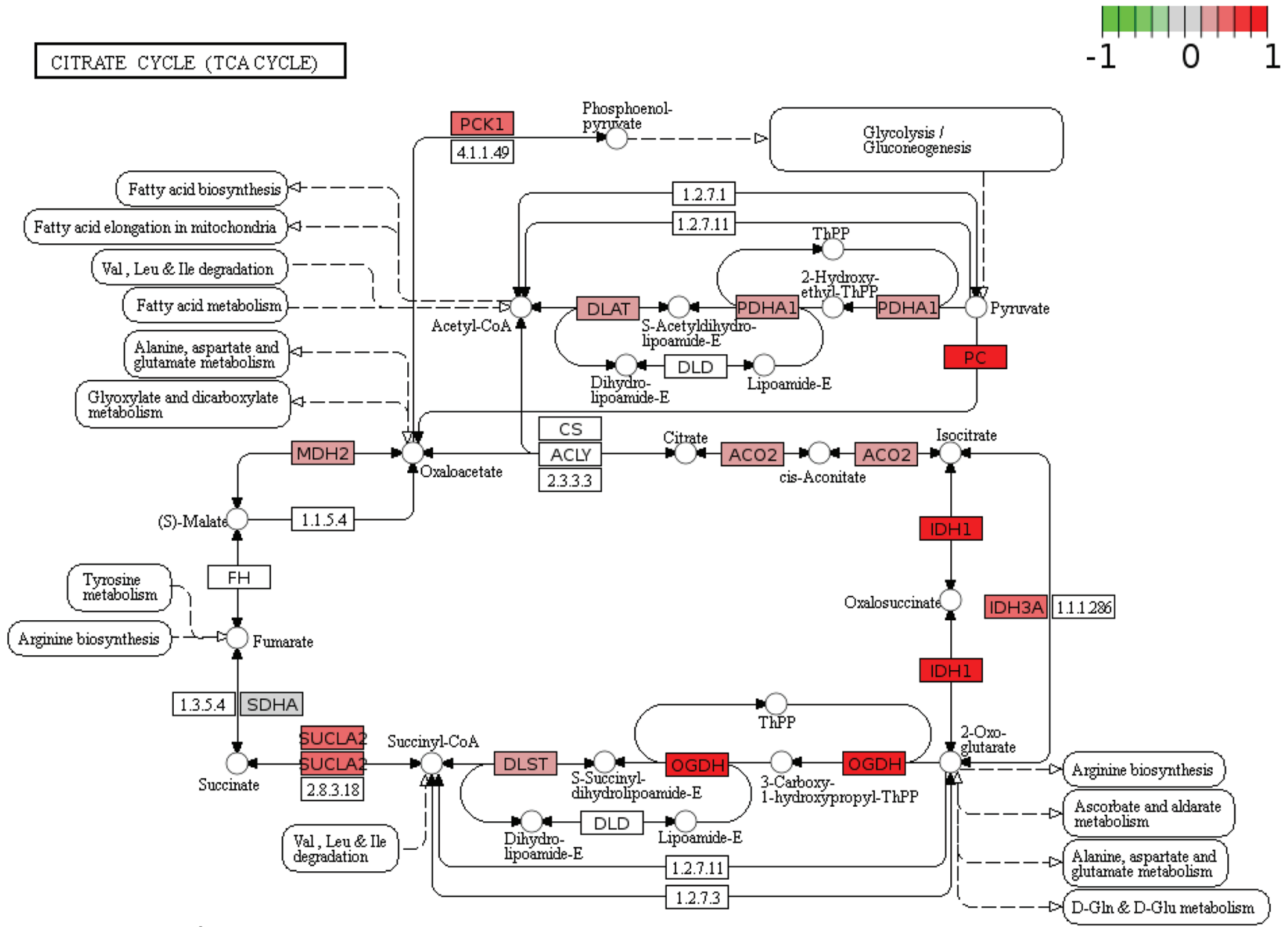

\section{Data on KEGG graph}

\section{Rendered by Pathview}

Figure 7. Differently expressed genes (DEG) of postpartum versus prepartum dairy cows in the Kyoto Encyclopedia of Genes and Genomes (KEGG) citrate cycle pathway. Changes of direction of DEG are mapped by colors. Green indicates genes were downregulated. Red indicates genes were upregulated. TCA = tricarboxylic acid; $\mathrm{PC}=$ pyruvate carboxylase; $\mathrm{PCK} 1=$ phosphoenolpyruvate carboxykinase $1 ; \mathrm{MDH} 2=$ malate dehydrogenase 2 . 


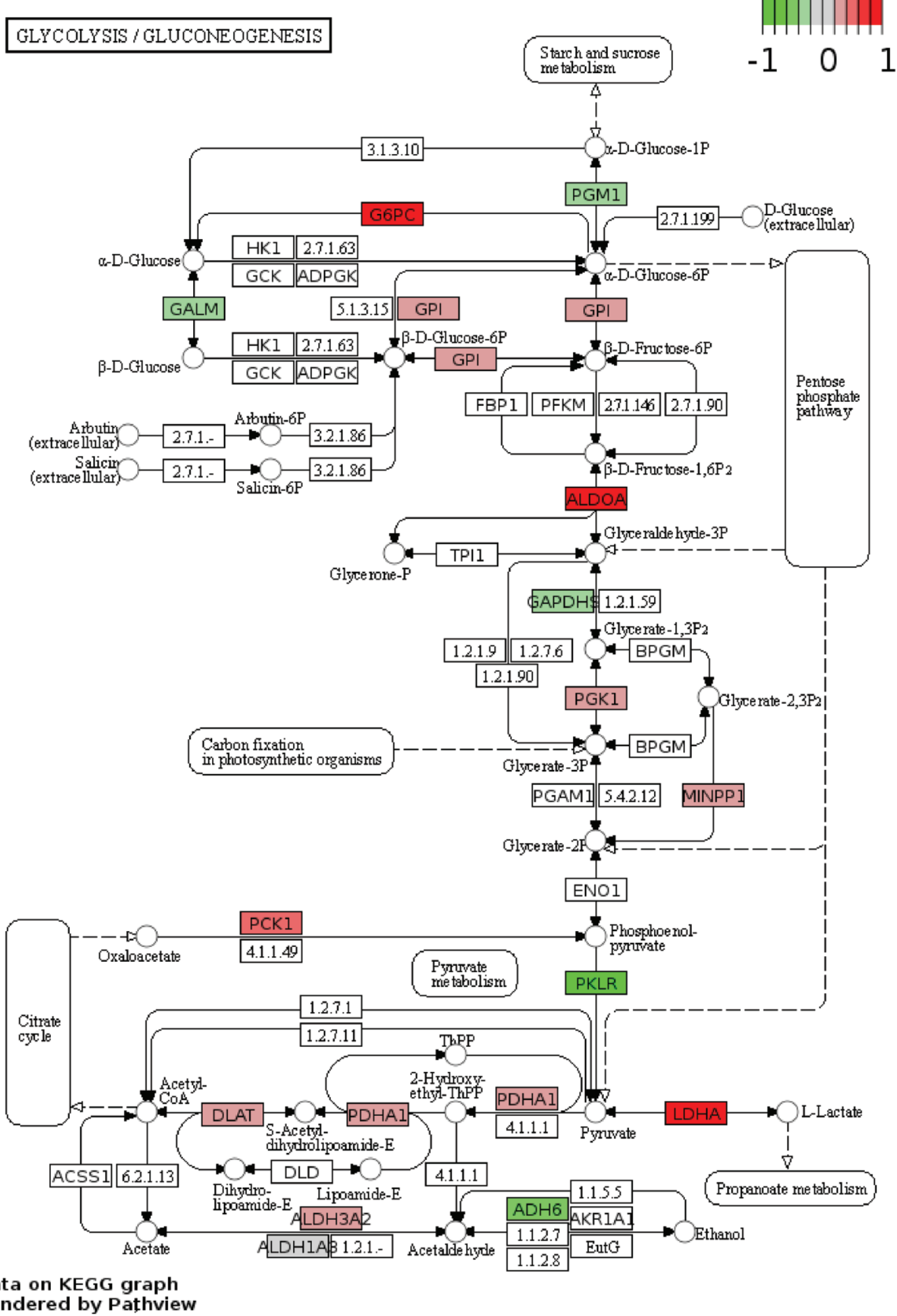

Figure 8. Differently expressed genes (DEG) of postpartum versus prepartum dairy cows in the Kyoto Encyclopedia of Genes and Genomes (KEGG) glycolysis and gluconeogenesis pathway. Changes of direction of DEG are mapped by colors. Green indicates genes were downregulated. Red indicates genes were upregulated. PCK1 = phosphoenolpyruvate carboxykinase 1; PGM1 = phosphoglucomutase 1. 
flammation (Moyes et al., 2016). In that experiment, increased protein synthesis in the ER and increase in protein export were also observed. Further support for a mild inflammatory response of the liver is also provided by the inhibition of xenobiotic metabolism in the liver in Post-P compared with Pre-P cows, particularly the P450 system, which is known to be inhibited by inflammation (Morgan, 2009).

\section{Co-Expression Network Analysis}

Co-expression network analysis provides insights into the coordinated transcriptomic response, suggesting common biological functions (Li et al., 2016). This is a systems biology approach for transcriptome data analyses that identifies highly connected genes that may be important to control the expression of other genes (Contreras-López et al., 2018).

In the first cluster of the network, the upregulated DEG were enriched with the processes mainly associated with protein synthesis and energy metabolism (cluster 1, Supplemental Figure S9, https://doi.org/ 10.3168/jds.2020-19101). Herein, the purpose of the mitochondrial gene expression machinery is to provide the 13 proteins of the oxidative phosphorylation system (Pearce et al., 2017). In addition, the induction of protein import in mitochondrial matrix indicated that more proteins from the cytosol were transported into mitochondria, increasing their number and activity (Endo et al., 2011), including energy metabolism (e.g., oxidative phosphorylation). Modification of RNA, including $5^{\prime}$ cap and $3^{\prime}$ poly(A) tail modifications, is known to promote mRNA stability and facilitate nuclear export, translation initiation, and recycling (Roundtree et al., 2017). Increased poly(A) formation and poly(A) tail modifications can be associated with increased functional specialization of the liver but can also increase efficiency of mRNA translation (Shepard et al., 2011). The coupling of oxidative phosphorylation and RNA modification in the same cluster might suggest a coordinated association between production of energy and protein synthesis.

It is noteworthy that inhibition of the regulation of insulin receptor signaling pathway and induction of fatty acid metabolic process and long-chain fatty acid transport emerged in the same cluster (cluster 2; Supplemental Figures S10, S11, and S12, https://doi .org/10.3168/jds.2020-19101). Weber et al. (2017) demonstrated that the mRNA abundance of $A C A D V L$ and $H M G C S 1$ in the liver of transition cows increased from 5 wk prepartum to $3 \mathrm{wk}$ postpartum, whereas administration of insulin using euglycemic-hyperinsulinemic clamps decreased the mRNA expression of CPT1A and $A C A D V L$, implying an inhibition of $\beta$-oxidation induced by insulin administration (Weber et al., 2017). Interestingly, insulin concentration in blood decreases substantially early postpartum (Reynolds et al., 2003; Graber et al., 2010). In the postprandial state in humans, insulin stimulates de novo lipogenesis and suppresses fatty acid oxidation in the liver (Leavens and Birnbaum, 2011), whereas mice lacking the insulin receptor in hepatocytes have increased fatty acid oxidation and failed to induce de novo lipogenesis in response to a meal (Biddinger et al., 2008; Haas et al., 2012). Thus, our results might suggest that reduced insulin signaling is important to allow fatty acid oxidation in the liver of Post-P cows.

Almost all the DEG in cluster 3 were upregulated and were mainly annotated to the biological process associated with cell proliferation, energy, and lipid metabolism (Supplemental Figure S13, https://doi.org/10 $.3168 /$ jds.2020-19101). The induced cell proliferation was also revealed by all the bioinformatic tools we used, including induction of the cell cycle and inhibition of apoptosis. The observed association between induced ATP synthesis and cell cycle process is indicative of the use of energy for the increase in hepatic cell proliferation (Morita et al., 2015).

\section{CONCLUSIONS}

Our study focused on early-postpartum adaptation using only 2 time points; thus, it is difficult to capture with such a data set the whole dynamic adaptation of the liver to lactation. To capture such adaptation, more time points using the same number of animals should be analyzed. Despite this limitation, our RNAseq analysis performed in a large number of animals revealed a substantial transcriptomic adaptation of the liver early postpartum. The bioinformatic analysis of the data confirmed that the major adaptation of the liver to the early postpartum period in cows is metabolic, chiefly lipid metabolism, with fatty acid oxidation and mitochondria playing a major role. The data confirmed a major role of PPAR and revealed the role of the adipose tissues via adipocytokines in such an adaptation. Our data also confirmed increased gluconeogenesis (but with an unexplained reduction of glucose transport) and cell proliferation, with a possible response to inflammatory-like conditions that may have reduced the capability of the liver to clear xenobiotics. Such data, together with prior findings of a strong response of the liver to energy level in the diet (Dann et al., 2006; Shahzad et al., 2014b), appears to support the management of transition cows focusing on priming the liver metabolically via PPAR to face early-postpartum metabolic challenges. 


\section{ACKNOWLEDGMENTS}

We are very grateful to Z. K. Zhou, from the Institute of Animal Science of Chinese Academy of Agricultural Sciences (Beijing) for his great contribution to the sequencing data processing. This research was partially supported by the National Key Research and Development Program of China (2018YFD0501600; Beijing), the Scientific Research Project for Major Achievements of the Agricultural Science and Technology Innovation Program (ASTIP; CAAS-ZDXT2019004,ASTIP-IAS071,CAAS-XTCX2016011-01; Beijing), and the Beijing Dairy Industry Innovation Team (BAIC06-2020). We give special thanks to our former and current students who have contributed to the projects. The authors have not stated any conflicts of interest.

\section{REFERENCES}

Acebron, S. P., E. Karaulanov, B. S. Berger, Y. L. Huang, and C. Niehrs. 2014. Mitotic wnt signaling promotes protein stabilization and regulates cell size. Mol. Cell 54:663-674. https://doi.org/10 .1016/j.molcel.2014.04.014.

Akins, M. S., S. J. Bertics, M. T. Socha, and R. D. Shaver. 2013. Effects of cobalt supplementation and vitamin B12 injections on lactation performance and metabolism of Holstein dairy cows. J. Dairy Sci. 96:1755-1768. https://doi.org/10.3168/jds.2012-5979.

Amatya, N., A. V. Garg, and S. L. Gaffen. 2017. IL-17 signaling: The Yin and the Yang. Trends Immunol. 38:310-322. https://doi.org/ 10.1016/j.it.2017.01.006.

Aoyama, T., Y. H. Paik, and E. Seki. 2010. Toll-like receptor signaling and liver fibrosis. Gastroenterol. Res. Pract. 2010:192543.

Aschenbach, J. R., N. B. Kristensen, S. S. Donkin, H. M. Hammon, and G. B. Penner. 2010. Gluconeogenesis in dairy cows: The secret of making sweet milk from sour dough. IUBMB Life 62:869-877. https://doi.org/10.1002/iub.400.

Bell, A. W. 1995. Regulation of organic nutrient metabolism during transition from late pregnancy to early lactation. J. Anim. Sci. 73:2804-2819. https://doi.org/10.2527/1995.7392804x.

Bergman, E. N., R. J. Havel, B. M. Wolfe, and T. Bohmer. 1971. Quantitative studies of the metabolism of chylomicron triglycerides and cholesterol by liver and extrahepatic tissues of sheep and dogs. J. Clin. Invest. 50:1831-1839. https://doi.org/10.1172/ JCI106674.

Bertoni, G., E. Trevisi, X. Han, and M. Bionaz. 2008. Effects of inflammatory conditions on liver activity in puerperium period and consequences for performance in dairy cows. J. Dairy Sci. 91:33003310. https://doi.org/10.3168/jds.2008-0995.

Bertoni, G., E. Trevisi, and R. Lombardelli. 2009. Some new aspects of nutrition, health conditions and fertility of intensively reared dairy cows. Ital. J. Anim. Sci. 8:491-518. https://doi.org/10.4081/ ijas.2009.491.

Biddinger, S. B., A. Hernandez-Ono, C. Rask-Madsen, J. T. Haas, J. O. Alemán, R. Suzuki, E. F. Scapa, C. Agarwal, M. C. Carey, G. Stephanopoulos, D. E. Cohen, G. L. King, H. N. Ginsberg, and C. R. Kahn. 2008. Hepatic insulin resistance is sufficient to produce dyslipidemia and susceptibility to atherosclerosis. Cell Metab. 7:125-134. https://doi.org/10.1016/j.cmet.2007.11.013.

Bindea, G., B. Mlecnik, H. Hackl, P. Charoentong, M. Tosolini, A. Kirilovsky, W. H. Fridman, F. Pages, Z. Trajanoski, and J. Galon. 2009. ClueGO: A Cytoscape plug-in to decipher functionally grouped gene ontology and pathway annotation networks. Bioinformatics 25:1091-1093. https://doi.org/10.1093/bioinformatics/ btp101.

Bionaz, M., S. Chen, M. J. Khan, and J. J. Loor. 2013. Functional role of PPARs in ruminants: Potential targets for fine-tuning metabo- lism during growth and lactation. PPAR Res. 2013:684159. https: //doi.org/10.1155/2013/684159.

Bionaz, M., and J. J. Loor. 2012. Ruminant metabolic systems biology: reconstruction and integration of transcriptome dynamics underlying functional responses of tissues to nutrition and physiological state. Gene Regul. Syst. Bio. 6:109-125. https://doi.org/ $10.4137 /$ GRSB.S9852.

Bionaz, M., J. Osorio, and J. J. Loor. 2015. Triennial Lactation Symposium: Nutrigenomics in dairy cows: Nutrients, transcription factors, and techniques. J. Anim. Sci. 93:5531-5553. https://doi.org/ 10.2527/jas.2015-9192.

Bionaz, M., K. Periasamy, S. L. Rodriguez-Zas, W. L. Hurley, and J. J. Loor. 2012. A novel dynamic impact approach (DIA) for functional analysis of time-course omics studies: Validation using the bovine mammary transcriptome. PLoS One 7:e32455. https://doi .org/10.1371/journal.pone.0032455.

Bionaz, M., E. Trevisi, L. Calamari, F. Librandi, A. Ferrari, and G. Bertoni. 2007. Plasma paraoxonase, health, inflammatory conditions, and liver function in transition dairy cows. J. Dairy Sci. 90:1740-1750. https://doi.org/10.3168/jds.2006-445.

Bobe, G., J. W. Young, and D. C. Beitz. 2004. Invited review: Pathology, etiology, prevention, and treatment of fatty liver in dairy cows. J. Dairy Sci. 87:3105-3124. https://doi.org/10.3168/jds .S0022-0302(04)73446-3.

Bradford, B. J., K. Yuan, J. K. Farney, L. K. Mamedova, and A. J. Carpenter. 2015. Invited review: Inflammation during the transition to lactation: New adventures with an old flame. J. Dairy Sci. 98:6631-6650. https://doi.org/10.3168/jds.2015-9683.

Bu, D., M. Bionaz, M. Wang, X. Nan, L. Ma, and J. Wang. 2017. Transcriptome difference and potential crosstalk between liver and mammary tissue in mid-lactation primiparous dairy cows. PLoS One 12:e0173082. https://doi.org/10.1371/journal.pone.0173082.

Busato, S., and M. Bionaz. 2020. The interplay between non-esterified fatty acids and bovine peroxisome proliferator-activated receptors: Results of a hybrid in vitro approach. J. Anim. Sci. Biotechnol. 11:91. https://doi.org/10.1186/s40104-020-00481-y.

Cao, H. 2014. Adipocytokines in obesity and metabolic disease. J. Endocrinol. 220:T47-T59. https://doi.org/10.1530/JOE-13-0339.

Contreras-López, O., T. C. Moyano, D. C. Soto, and R. A. Gutiérrez. 2018. Step-by-step construction of gene co-expression networks from high-throughput Arabidopsis RNA sequencing data. Methods Mol. Biol. 1761:275-301. https://doi.org/10.1007/978-1-4939 $-7747-521$.

Dann, H. M., N. B. Litherland, J. P. Underwood, M. Bionaz, A. D'Angelo, J. W. McFadden, and J. K. Drackley. 2006. Diets during far-off and close-up dry periods affect periparturient metabolism and lactation in multiparous cows. J. Dairy Sci. 89:3563-3577. https://doi.org/10.3168/jds.S0022-0302(06)72396-7.

Davis, A. N., J. E. Rico, W. A. Myers, M. J. Coleman, M. E. Clapham, N. J. Haughey, and J. W. McFadden. 2019. Circulating lowdensity lipoprotein ceramide concentrations increase in Holstein dairy cows transitioning from gestation to lactation. J. Dairy Sci. 102:5634-5646. https://doi.org/10.3168/jds.2018-15850.

Dohoo, I. R., and S. W. Martin. 1984. Subclinical ketosis: Prevalence and associations with production and disease. Can. J. Comp. Med. $48: 1-5$.

Dong, X., A. Yambartsev, S. A. Ramsey, L. D. Thomas, N. Shulzhenko, and A. Morgun. 2015. Reverse enGENEering of regulatory networks from Big Data: A roadmap for biologists. Bioinform. Biol. Insights 9:61-74. https://doi.org/10.4137/BBI.S12467.

Drackley, J. K. 1999. ADSA Foundation Scholar Award: Biology of dairy cows during the transition period: The final frontier? J. Dairy Sci. 82:2259-2273. https://doi.org/10.3168/jds.S0022 $-0302(99) 75474-3$

Drackley, J. K., A. D. Beaulieu, and J. P. Elliott. 2001. Responses of milk fat composition to dietary fat or nonstructural carbohydrates in Holstein and Jersey cows. J. Dairy Sci. 84:1231-1237. https:// doi.org/10.3168/jds.S0022-0302(01)74584-5.

Drackley, J. K., H. M. Dann, N. Douglas, N. A. J. Guretzky, N. B. Litherland, J. P. Underwood, and J. J. Loor. 2005. Physiological and pathological adaptations in dairy cows that may increase sus- 
ceptibility to periparturient diseases and disorders. Ital. J. Anim. Sci. 4:323-344. https://doi.org/10.4081/ijas.2005.323.

Duffield, T., R. Bagg, L. DesCoteaux, E. Bouchard, M. Brodeur, D. DuTremblay, G. Keefe, S. LeBlanc, and P. Dick. 2002. Prepartum monensin for the reduction of energy associated disease in postpartum dairy cows. J. Dairy Sci. 85:397-405. https://doi.org/10.3168/ jds.S0022-0302(02)74087-3.

Endo, T., K. Yamano, and S. Kawano. 2011. Structural insight into the mitochondrial protein import system. Biochim. Biophys. Acta 1808:955-970.

Esposito, G., P. C. Irons, E. C. Webb, and A. Chapwanya. 2014. Interactions between negative energy balance, metabolic diseases, uterine health and immune response in transition dairy cows. Anim. Reprod. Sci. 144:60-71. https://doi.org/10.1016/j.anireprosci.2013 .11.007.

Girma, D. D., L. Ma, F. Wang, Q. R. Jiang, T. R. Callaway, J. K. Drackley, and D. P. Bu. 2019. Effects of close-up dietary energy level and supplementing rumen-protected lysine on energy metabolites and milk production in transition cows. J. Dairy Sci. 102:7059-7072. https://doi.org/10.3168/jds.2018-15962.

Graber, M., S. Kohler, T. Kaufmann, M. G. Doherr, R. M. Bruckmaier, and H. A. van Dorland. 2010. A field study on characteristics and diversity of gene expression in the liver of dairy cows during the transition period. J. Dairy Sci. 93:5200-5215. https://doi.org/ $10.3168 /$ jds.2010-3265.

Graulet, B., J. J. Matte, A. Desrochers, L. Doepel, M. F. Palin, and C. L. Girard. 2007. Effects of dietary supplements of folic acid and vitamin B12 on metabolism of dairy cows in early lactation. J. Dairy Sci. 90:3442-3455. https://doi.org/10.3168/jds.2006-718.

Greenfield, R. B., M. J. Cecava, and S. S. Donkin. 2000. Changes in mRNA expression for gluconeogenic enzymes in liver of dairy cattle during the transition to lactation. J. Dairy Sci. 83:1228-1236. https://doi.org/10.3168/jds.S0022-0302(00)74989-7.

Grum, D. E., J. K. Drackley, R. S. Younker, D. W. LaCount, and J. J. Veenhuizen. 1996. Nutrition during the dry period and hepatic lipid metabolism of periparturient dairy cows. J. Dairy Sci. 79:18501864. https://doi.org/10.3168/jds.S0022-0302(96)76553-0.

Grummer, R. R. 1995. Impact of changes in organic nutrient metabolism on feeding the transition dairy cow. J. Anim. Sci. 73:28202833. https://doi.org/10.2527/1995.7392820x.

Ha, N. T., C. Drögemüller, C. Reimer, F. Schmitz-Hsu, R. M. Bruckmaier, H. Simianer, and J. J. Gross. 2017. Liver transcriptome analysis reveals important factors involved in the metabolic adaptation of the transition cow. J. Dairy Sci. 100:9311-9323. https:// doi.org/10.3168/jds.2016-12454.

Haas, J. T., J. Miao, D. Chanda, Y. Wang, E. Zhao, M. E. Haas, M. Hirschey, B. Vaitheesvaran, R. V. Farese Jr., I. J. Kurland, M. Graham, R. Crooke, F. Foufelle, and S. B. Biddinger. 2012. Hepatic insulin signaling is required for obesity-dependent expression of SREBP-1c mRNA but not for feeding-dependent expression. Cell Metab. 15:873-884. https://doi.org/10.1016/j.cmet.2012.05.002.

Han, H.-S., G. Kang, J. S. Kim, B. H. Choi, and S.-H. Koo. 2016. Regulation of glucose metabolism from a liver-centric perspective. Exp. Mol. Med. 48:e218. https://doi.org/10.1038/emm.2015.122.

Heallen, T., M. Zhang, J. Wang, M. Bonilla-Claudio, E. Klysik, R. L. Johnson, and J. F. Martin. 2011. Hippo pathway inhibits Wnt signaling to restrain cardiomyocyte proliferation and heart size. Science 332:458-461. https://doi.org/10.1126/science.1199010.

Huang, D. W., B. T. Sherman, and R. A. Lempicki. 2009. Systematic and integrative analysis of large gene lists using DAVID bioinformatics resources. Nat. Protoc. 4:44-57. https://doi.org/10.1038/ nprot.2008.211.

Huang, J., S. Wu, J. Barrera, K. Matthews, and D. Pan. 2005. The Hippo signaling pathway coordinately regulates cell proliferation and apoptosis by inactivating Yorkie, the Drosophila Homolog of YAP. Cell 122:421-434. https://doi.org/10.1016/j.cell.2005.06.007.

Jin, G. Z., Y. Zhang, W. M. Cong, X. Wu, X. Wang, S. Wu, S. Wang, W. Zhou, S. Yuan, H. Gao, G. Yu, and W. Yang. 2018. Phosphoglucomutase 1 inhibits hepatocellular carcinoma progression by regulating glucose trafficking. PLoS Biol. 16:e2006483. https://doi .org/10.1371/journal.pbio.2006483.
Karim, S., D. H. Adams, and P. F. Lalor. 2012. Hepatic expression and cellular distribution of the glucose transporter family. World J. Gastroenterol. 18:6771-6781. https://doi.org/10.3748/wjg.v18 ii46.6771.

Kessler, E. C., J. J. Gross, R. M. Bruckmaier, and C. Albrecht. 2014 Cholesterol metabolism, transport, and hepatic regulation in dairy cows during transition and early lactation. J. Dairy Sci. 97:54815490. https://doi.org/10.3168/jds.2014-7926.

Kinoshita, A., L. Locher, R. Tienken, U. Meyer, S. Danicke, J. Rehage, and K. Huber. 2016. Associations between Forkhead box O1 (FoxO1) expression and indicators of hepatic glucose production in transition dairy cows supplemented with dietary nicotinic acid. PLoS One 11:e0146670. https://doi.org/10.1371/journal.pone .0146670 .

Kremer, W. D., E. N. Noordhuizen-Stassen, F. J. Grommers, Y. H. Schukken, R. Heeringa, A. Brand, and C. Burvenich. 1993. Severity of experimental Escherichia coli mastitis in ketonemic and nonketonemic dairy cows. J. Dairy Sci. 76:3428-3436. https://doi .org/10.3168/jds.S0022-0302(93)77681-X.

Langmead, B., and S. L. Salzberg. 2012. Fast gapped-read alignment with Bowtie 2. Nat. Methods 9:357-359. https://doi.org/10.1038/ nmeth.1923.

Leavens, K. F., and M. J. Birnbaum. 2011. Insulin signaling to hepatic lipid metabolism in health and disease. Crit. Rev. Biochem. Mol Biol. 46:200-215. https://doi.org/10.3109/10409238.2011.562481.

Li, L., R. Briskine, R. Schaefer, P. S. Schnable, C. L. Myers, L. E. Flagel, N. M. Springer, and G. J. Muehlbauer. 2016. Co-expression network analysis of duplicate genes in maize (Zea mays L.) reveals no subgenome bias. BMC Genomics 17:875. https://doi.org/10 $.1186 / \mathrm{s} 12864-016-3194-0$.

Lomax, M. A., and G. D. Baird. 1983. Blood flow and nutrient exchange across the liver and gut of the dairy cow: Effects of lactation and fasting. Br. J. Nutr. 49:481-496. https://doi.org/10.1079/ BJN19830057.

Loor, J. J., M. Bionaz, and J. K. Drackley. 2013. Systems physiology in dairy cattle: Nutritional genomics and beyond. Annu. Rev. Anim. Biosci. 1:365-392. https://doi.org/10.1146/annurev-animal -031412-103728.

Loor, J. J., H. M. Dann, R. E. Everts, R. Oliveira, C. A. Green, N. A. Guretzky, S. L. Rodriguez-Zas, H. A. Lewin, and J. K. Drackley. 2005. Temporal gene expression profiling of liver from periparturient dairy cows reveals complex adaptive mechanisms in hepatic function. Physiol. Genomics 23:217-226. https://doi.org/10.1152/ physiolgenomics.00132.2005.

Loor, J. J., R. E. Everts, M. Bionaz, H. M. Dann, D. E. Morin, R. Oliveira, S. L. Rodriguez-Zas, J. K. Drackley, and H. A. Lewin. 2007. Nutrition-induced ketosis alters metabolic and signaling gene networks in liver of periparturient dairy cows. Physiol. Genomics 32:105-116. https://doi.org/10.1152/physiolgenomics.00188.2007.

Love, M. I., W. Huber, and S. Anders. 2014. Moderated estimation of fold change and dispersion for RNA-seq data with DESeq2. Genome Biol. 15:550. https://doi.org/10.1186/s13059-014-0550-8.

Luo, W., G. Pant, Y. K. Bhavnasi, S. G. Blanchard Jr., and C. Brouwer. 2017. Pathview Web: User friendly pathway visualization and data integration. Nucleic Acids Res. 45(W1):W501-W508. https:/ /doi.org/10.1093/nar/gkx372.

Marmor, M. D., K. B. Skaria, and Y. Yarden. 2004. Signal transduction and oncogenesis by ErbB/HER receptors. Int. J. Radiat. Oncol. Biol. Phys. 58:903-913. https://doi.org/10.1016/j.ijrobp.2003 .06 .002 .

McCabe, M., S. Waters, D. Morris, D. Kenny, D. Lynn, and C. Creevey. 2012. RNA-seq analysis of differential gene expression in liver from lactating dairy cows divergent in negative energy balance. BMC Genomics 13:193. https://doi.org/10.1186/1471-2164-13-193.

Morgan, E. T. 2009. Impact of infectious and inflammatory disease on cytochrome P450-mediated drug metabolism and pharmacokinetics. Clin. Pharmacol. Ther. 85:434-438. https://doi.org/10.1038/ clpt.2008.302.

Morita, M., S.-P. Gravel, L. Hulea, O. Larsson, M. Pollak, J. St-Pierre, and I. Topisirovic. 2015. mTOR coordinates protein synthesis, 
mitochondrial activity and proliferation. Cell Cycle 14:473-480. https://doi.org/10.4161/15384101.2014.991572.

Moyes, K. M., P. Sorensen, and M. Bionaz. 2016. The impact of intramammary Escherichia coli challenge on liver and mammary transcriptome and cross-talk in dairy cows during early lactation using RNAseq. PLoS One 11:e0157480. https://doi.org/10.1371/journal .pone.0157480.

National Genomics Data Center Members and Partners. 2020. Database resources of the National Genomics Data Center in 2020. Nucleic Acids Res. 48(D1):D24-D33.

Nordlie, R. C., J. D. Foster, and A. J. Lange. 1999. Regulation of glucose production by the liver. Annu. Rev. Nutr. 19:379-406. https: //doi.org/10.1146/annurev.nutr.19.1.379.

NRC. 2001. Nutrient Requirements of Dairy Cattle. 7th Rev. Ed. National Academies Press, Washington, DC.

Pearce, S. F., P. Rebelo-Guiomar, A. R. D'Souza, C. A. Powell, L. Van Haute, and M. Minczuk. 2017. Regulation of mammalian mitochondrial gene expression: Recent advances. Trends Biochem. Sci. 42:625-639. https://doi.org/10.1016/j.tibs.2017.02.003.

Pertea, M., D. Kim, G. M. Pertea, J. T. Leek, and S. L. Salzberg. 2016. Transcript-level expression analysis of RNA-seq experiments with HISAT, StringTie and Ballgown. Nat. Protoc. 11:1650-1667. https://doi.org/10.1038/nprot.2016.095.

Piñeiro-Carrero, V. M., and E. O. Piñeiro. 2004. Liver. Pediatrics 113(Suppl. 3):1097.

Preynat, A., H. Lapierre, M. C. Thivierge, M. F. Palin, N. Cardinault, J. J. Matte, A. Desrochers, and C. L. Girard. 2010. Effects of supplementary folic acid and vitamin $\mathrm{B}(12)$ on hepatic metabolism of dairy cows according to methionine supply. J. Dairy Sci. 93:2130-2142. https://doi.org/10.3168/jds.2009-2796.

Qin, N., T. Kokkonen, S. Salin, T. Seppänen-Laakso, J. Taponen, A. Vanhatalo, and K. Elo. 2018. Prepartal high-energy feeding with grass silage-based diets does not disturb the hepatic adaptation of dairy cows during the periparturient period. J. Dairy Sci. 101:8929-8943. https://doi.org/10.3168/jds.2017-13153.

Ren, H., G. Wang, L. Chen, J. Jiang, L. Liu, N. Li, J. Zhao, X. Sun, and P. Zhou. 2016. Genome-wide analysis of long non-coding RNAs at early stage of skin pigmentation in goats (Capra hircus). BMC Genomics 17:67. https://doi.org/10.1186/s12864-016-2365 -3 .

Reynolds, C. K., P. C. Aikman, B. Lupoli, D. J. Humphries, and D. E. Beever. 2003. Splanchnic metabolism of dairy cows during the transition from late gestation through early lactation. J. Dairy Sci. 86:1201-1217. https://doi.org/10.3168/jds.S0022-0302(03)73704 -7 .

Reynolds, C. K., B. Durst, B. Lupoli, D. J. Humphries, and D. E. Beever. 2004. Visceral tissue mass and rumen volume in dairy cows during the transition from late gestation to early lactation. J. Dairy Sci. 87:961-971. https://doi.org/10.3168/jds.S0022 -0302(04)73240-3.

Roche, J. R., C. R. Burke, M. A. Crookenden, A. Heiser, J. L. Loor, S. Meier, M. D. Mitchell, C. V. C. Phyn, and S. A. Turner. 2017. Fer- tility and the transition dairy cow. Reprod. Fertil. Dev. 30:85-100. https://doi.org/10.1071/RD17412.

Roundtree, I. A., M. E. Evans, T. Pan, and C. He. 2017. Dynamic RNA modifications in gene expression regulation. Cell 169:11871200. https://doi.org/10.1016/j.cell.2017.05.045.

Schäff, C., S. Börner, S. Hacke, U. Kautzsch, D. Albrecht, H. M. Hammon, M. Röntgen, and B. Kuhla. 2012. Increased anaplerosis, TCA cycling, and oxidative phosphorylation in the liver of dairy cows with intensive body fat mobilization during early lactation. J. Proteome Res. 11:5503-5514. https://doi.org/10.1021/pr300732n.

Schlegel, G., R. Ringseis, J. Keller, F. J. Schwarz, and K. Eder. 2012 Changes in the expression of hepatic genes involved in cholesterol homeostasis in dairy cows in the transition period and at different stages of lactation. J. Dairy Sci. 95:3826-3836. https://doi.org/10 $.3168 /$ jds.2011-5221.

Shahzad, K., M. Bionaz, E. Trevisi, G. Bertoni, S. L. Rodriguez-Zas, and J. J. Loor. 2014a. Integrative analyses of hepatic differentially expressed genes and blood biomarkers during the peripartal period between dairy cows overfed or restricted-fed energy prepartum. PLoS One 9:e99757. https://doi.org/10.1371/journal.pone .0099757.

Shahzad, K., M. Bionaz, E. Trevisi, G. Bertoni, S. L. Rodriguez-Zas, and J. J. Loor. 2014b. Integrative analyses of hepatic differentially expressed genes and blood biomarkers during the peripartal period between dairy cows overfed or restricted-fed energy prepartum. PLoS One 9:e99757. https://doi.org/10.1371/journal.pone .0099757.

Shepard, P. J., E.-A. Choi, J. Lu, L. A. Flanagan, K. J. Hertel, and Y. Shi. 2011. Complex and dynamic landscape of RNA polyadenylation revealed by PAS-Seq. RNA 17:761-772. https://doi.org/10 $.1261 /$ rna.2581711.

Trefts, E., M. Gannon, and D. H. Wasserman. 2017. The liver. Curr. Biol. 27:R1147-R1151. https://doi.org/10.1016/j.cub.2017.09.019

Wang, Y., F. Song, J. Zhu, S. Zhang, Y. Yang, T. Chen, B. Tang, L. Dong, N. Ding, Q. Zhang, Z. Bai, X. Dong, H. Chen, M. Sun, S. Zhai, Y. Sun, L. Yu, L. Lan, J. Xiao, X. Fang, H. Lei, Z. Zhang, and W. Zhao. 2017. GSA: Genome Sequence Archive. Genomics Proteomics Bioinformatics 15:14-18. https://doi.org/10.1016/ j.gpb.2017.01.001.

Weber, C., C. T. Schäff, U. Kautzsch, S. Börner, S. Erdmann, R. M. Bruckmaier, M. Röntgen, B. Kuhla, and H. M. Hammon. 2017. Variable liver fat concentration as a proxy for body fat mobilization postpartum has minor effects on insulin-induced changes in hepatic gene expression related to energy metabolism in dairy cows. J. Dairy Sci. 100:1507-1520. https://doi.org/10.3168/jds .2016-11808.

Zhao, F. Q., and A. F. Keating. 2007. Functional properties and genomics of glucose transporters. Curr. Genomics 8:113-128. https:/ /doi.org/10.2174/138920207780368187. 